\title{
EXPLORING EXPERIENCES OF GRIEF AND LOSS AFTER SUICIDE OF A LOVED ONE IN SOUTH ASIAN FAMILIES
}

\author{
by
}

Sanjini Phillips, BSW, Ryerson University, 2010

\author{
An MRP \\ presented to Ryerson University \\ in partial fulfillment of the \\ requirements for the degree of \\ Master of Social Work \\ in the Program of \\ Social Work
}

Toronto, Ontario, Canada, 2017

(C) Sanjini Phillips 2017 


\section{AUTHOR'S DECLARATION FOR ELECTRONIC SUBMISSION OF A MRP}

I hereby declare that I am the sole author of this MRP. This is a true copy of the MRP, including any required final revisions.

I authorize Ryerson University to lend this MRP to other institutions or individuals for the purpose of scholarly research

I further authorize Ryerson University to reproduce this MRP by photocopying or by other means, in total or in part, at the request of other institutions or individuals for the purpose of scholarly research.

I understand that my MRP may be made electronically available to the public. 


\begin{abstract}
Exploring Experiences of Grief and Loss after Suicide of a loved one in South Asian Families Master of Social Work, 2017

Sanjini Phillips

Program of Social Work, Ryerson University

This research explores the experiences of South Asian families who have experienced suicide of a loved one in the past five-years. Past research in the areas of suicide, grief, loss, and bereavement has not focused on how different cultures live through and may view these issues through a cultural lens. The research uses a qualitative narrative methodology and to explore how South Asian families understand and interpret suicide and negotiate their personal experiences of loss and grief after suicide. Individual interviews were conducted and recorded on audiotape. Participants were provided with an opportunity to explore and share their experiences of suicide of a loved one from a cultural perspective, voices that are missing in the mainstream literature. This research contributes to a broader understanding of suicide in diverse communities and how helping professionals can work towards a more inclusive practice with South Asian families who have experiences suicide.
\end{abstract}




\section{ACKNOWLEDGEMENTS}

I would like to acknowledge my mother and my sister for their support and encouragement throughout this process. Thank you, mom, for never allowing me to forget that it is never too late to finish what you started.

I would also like to acknowledge Dr. Jennifer Poole who started this writing with me in 2011 as my first supervisor. Thank you for encouraging me to write about something that was so deeply personal; even though it was difficult and at times and reading about suicide after losing my father was painful this was a journey that I'm glad I went on. Most importantly I would like to graciously thank Dr. Susan Preston my second supervisor. I honestly do not think that I would have made it through this without your constant guidance, support, and encouragement. Thank you for believing in me and dragging me to the finish line. Not many other professors would have been as hands on as you have so I will forever be grateful to you.

Lastly to my little baby on the way, I am excited to meet you and one day I hope that I will be encouraging you to not give up on your Masters. 


\section{DEDICATION}

Loss is a feeling in your gut. It's everything you anticipated and worse. It closes you off for a moment, a second, a year, years... It can bring you back to THE moment in a second. Nothing has changed, yet you see more. reality.

Loss is heartbreak, loss is a relief, loss is a never-ending ache; loss makes you face

Loss makes you remember, loss makes you feel; it's everything you hated and hide from; and yet it is everything you needed.

Thank you for sharing your pain in a way that won't be forgotten. Thank you for taking a stance that felt right to you. Thank you for being honest when none of us knew how to be. Thank you for everything you have ever taught me. Thank you for knowing I could only get here after you were gone.

To my father, I cannot express how much I love you, I just wish I had the nerve to say it to you when you were here. I wrote this in memory of you, so that people remember that a death cannot erase a meaningful and powerful life. 


\section{TABLE OF CONTENTS}

Chapter 1 Introduction

Chapter 2 Theoretical Framework

Chapter 3 Literature Review

Chapter 4 Methodology

Chapter 5 Findings

Chapter 6 Discussion

Chapter 7 Conclusion

References
Page \# 1

Page \# 3

Page \# 10

Page \# 29

Page \# 38

Page \# 61

Page \# 78

Page \# 80 


\section{CHAPTER 1. INTRODUCTION}

Losing a family member to suicide is a devastating experience. The bereavement, grief, and loss that one experiences after suicide of a loved one is 'different from 'normal' mourning behavior" (Armour, 2007 p. 55). The sudden and unexpected nature of the loss can significantly impact how an individual or family copes with death of a loved one. After surviving the loss of my parent by suicide I began to explore resources and supports for coping with suicide. What I found was that much of the literature was directed to and situated in Western understandings of death, grief and loss, and family and individual coping. The concept of culture and the impact of culture on suicide, grief, and loss was missing. Coming from a South Asian, multi-faith family, I wanted to know if my culture influenced how I was coping with death by suicide. I had many questions I wanted to consider: Was culture a protective factor? Did culture increase or decrease my acceptance of losing a family member to suicide? Was my grieving process impacted by my culture? By engaging in this research, I wanted to add to the current discourse on suicide, grief, and loss to ensure that "othered" voices and stories like mine are part of the complex understandings of grief and loss. As Ord (2009) states,

We cannot simply construct a "new model" of grief because society is increasingly diverse and fragmented; we must improve upon existing frameworks ... "The aim is not to destroy but to redefine and reorient what we do and what we know" (Chambon, 1999, p. 53). Ultimately there are critical possibilities for reconstructing and reclaiming grief therapy as a form of discursive resistance. (p. 197)

Given that "suicide is one of the leading causes of death for people of all ages [in Canada]" (Navaneelan, 2017), it is important to explore suicide, grief, and loss from a diverse, multifaceted perspective to ensure that supports and service are inclusive and varied to speak to 
all Canadians who have survived death by suicide of a family member. Suicide does not discriminate; suicide can be a risk factor to all people. Young people, elderly people, cis gendered (McConnell et al. 2016), people in the queer community (Haas 2010), people living with a disability (McConnell et al., 2016) are in higher risk categories for suicide. Similar to missing voices of people of colour, suicidality research has not explored the stories of all people and all identities. Instead the suicide, grief, and loss literature and research has ignored and dismissed 'othered voices' and relied on a homogenized approach that erases the lived realities and experiences of people on the margins. Although the scope of this paper is too small to address these gaps, it is important to acknowledge that there is unexplored knowledge in many diverse groups that needs to be brought to the forefront.

This research paper will provide a brief overview of some of the literature on suicide, grief, and loss from a South Asian perspective. The research conducted utilizes a qualitative narrative methodology and will focus on exploring how South Asian families understand and interpret suicide and negotiate their personal experiences of loss and grief after suicide of a loved one through interviews with participants. The findings and discussion will then be analyzed through a critical race framework. 


\section{CHAPTER 2. THEORETICAL FRAMEWORK}

"What there is to know is inextricably linked to an individual's past, present, and future. It is shaped by historical, social, political and economic experiences. My reality suggests that race matters"

(Dunbar, 2008, p.86).

When reviewing the literature on suicide, grief, and loss the one question that kept revolving through my mind was, why was I absent from the literature? Where was the literature that could assist me, or someone similar to me through the grief and loss after experiencing suicide of a loved one? Though there is an abundance of literature and studies on suicide, grief and loss none of them spoke to my experiences directly, I did not feel present. As the quote above by Dunbar (2008) illustrates, the positionality of the researcher and researched plays an important role in what is produced and from whose perspective. Historically, the majority of the research has been about white European people and conducted by white researchers, as exampled in the literature review. The issues, interpretations, and outcomes have been tailored to this majority. This base has become the "centre" of what is viewed as generally accepted and valid literature; those who do not fit within the centre or what is constituted as relevant to research, are situated and defined by those within the centre (Dunbar, 2008). As Marsh (2010) notes, the knowledge of people outside this dominant centre becomes hidden, or considered as, “insufficiently elaborated knowledges, naïve knowledges, hierarchically inferior knowledges, knowledge that are below the required level of erudition or scientificity and thus are disqualified or marginalized" (p. 72). As other ways of knowing are pushed aside and devalued, Western knowledge of suicide, grief, and loss has become grounded as the only way to approach these issues. This privileging of Western knowledge is problematic as it denies other ways of knowing as credible and important, and those other knowledges may be more relevant and informative in many contexts. I want to privilege those other ways of knowing, as they are particularly relevant 
to my exploration of experiences in the South Asian community. Thus, I have sought critical race theory and critical whiteness as the theoretical lens to guide my work.

Privileging Western knowledge becomes particularly problematic when those within the centre use their cultural understandings as a marker for what should be considered normal or common to all, without acknowledging that white European culture is not the universal, culture within the dominant group is sometimes invisible as European American researchers and participants view themselves as generic rather than ethnic individuals. This attitude often translates into over-attributions to culture in the case of ethnic minorities, and underestimates the role of culture with regard to issues involving the dominant ethnic group (Joe et al., 2008, p. 358).

This is especially evident when we look within early cross-cultural work within death, bereavement, suicide, and grief and loss where "othered" people's death rituals, mourning, or grief process were interpreted based on a Western centered epistemology as different, strange, romanticized or exotic or inferior or irrational (Valentine, 2006).

It has only been in the recent years that the need for a cultural perspective regarding suicide to be included in scholarship has been initiated. However, what has been done to date still lacks an ontological basis that highlights the multiple and layered experience of people on the margins. The majority of the current research on culture, suicide, grief and loss tends to utilize variables to compare the difference in preventative measures, risk/protective factors, nonfatal, fatal death rates or reduce culture to ethnicity, as discussed in the literature review. To move beyond a comparative analysis of different cultural groups versus the 'majority', the research must delve into worldviews of racialized people and start building a base of understanding that is rich and unique to the experience of others. 
In addition to this concern about the whiteness of literature regarding suicide, the experiences of other cultures should not be built against and/or rooted in the ways of knowing that are grounded in Western knowledge without any theoretical basis. As Joe et al. (2008) notes, though there has been an abundance of studies on suicidal behaviour, most of these studies have not been grounded in theory. Though there is ample discussion and hypothesizing on risk/protective factors there is a lack of theoretical foundation guiding suicide study. This lack of theoretical foundation could be one of the reasons that culture has been pushed to the side or even made invisible. As stronger theoretical base could ground how these issues are researched and by whom. In doing so, we could have a clearer base to understand and acknowledge why a richer broader conception of suicide, grief and loss is crucial to addressing the bereavement needs of all people.

It is no longer enough to create research that is only relevant to one segment of the population hidden under the guise of reaching out to those 'at risk', that somehow there is a universal approach to risk. As Owens and Randhawa (2004) note, "fixed ideas about difference and sameness can lead to racism or simplistic stereotyping of minority ethnic groups" (p. 417). Moving beyond an essentialized cultural understanding will enable researchers to highlight the negotiations that racialized people manage to work through, amidst the categorical 'boxes' they may be placed in on a daily basis, including when they experience the suicide of a loved one. This will emphasize how our ways of knowing are very different from Western understandings because of our varied positionality.

The advantage to scholars of colour result from the opportunity/obligation to transcend the either/or way of knowing...They provide multiple positions/lenses that challenge the dominant cultural model that they contend distorts their realities and has served only to 
sustain power relations that continue to place them at a disadvantage (Dunbar, 2008, p. 86).

I am utilizing Critical Race Theory (CRT) to ground my work as it speaks to challenging accepted dominant cultural ideology and also identifies the inclusion of voices of colour as a major tenet of CRT. Rocco et al (2014) provides an overview of CRT tenets:

The tenets are as follows: (a) Racism is endemic and ordinary permeating all aspects of society in such a way as to be unnoticed. (b) Race is a social construction that has no biological significance. (c) Differential racialization, means that different minority ... are racialized (become the least valued in society) at different times depending on economic need, geographic location, and current events. (d) Interest convergence and material determinism occur when the dominant group works to advance social justice for people of color or minority groups when both groups' interests, needs, or expectations converge especially for economic or material gain of the dominant group. (e) Intersectionality and anti-essentialism, is the notion that individuals do not have unitary identities instead many characteristics intersect in a person such as race, sex, class, national origin, sexual orientation, and therefore a person's identity cannot be reduced to one essential characteristic or identity. (f) Voice, is the notion that people of color (minority groups) have a unique voice which exists because of experience with historical and current oppression and as such they can share stories about oppression which Whites are unlikely to know because they have not experienced oppression in this way (p. 460).

For my purposes, I will be incorporating CRT in my own research in the understanding that race and racism are used to justify the social constructions that validate Western knowledge as the accepted universal norm and experience in grief and loss and suicide. From this 
perspective, I will be analyzing my findings by looking at the importance of the inclusion of South Asians voices that represent the varied subject positions of the South Asian identity and seek to ensure that these voices are not essentialized into one script or voice. As noted in Parker and Lynn (2002) "only through listening can the conviction of seeing the world one way be challenged and 'one can acquire the ability to see the world through others' eyes'" (p. 10). By listening to my participants, I hope that I will also be able to challenge normative constructions that have not recognized, that there are 'othered eyes' to understand the world from and that the inclusion of all voices enhances legitimized knowledge for all.

I will also be underpinning my research and analysis with an examination of how whiteness also upholds and encourages a devaluing of other perspectives. According to Jeyasingham (2012) whiteness is built upon notions of white privilege, invisibility of whiteness, and social constructions. As I have noted that there has been a privileging of white Western knowledge and to be able to disrupt these positions one must explore the role that whiteness has played in creating these privileged locations. "A primary goal of whiteness studies is to illuminate the everyday, invisible, subtle, cultural and social practices, ideas and codes that discursively secure the power and privilege of white people, but that strategically remains unmarked, unnamed, and unmapped in contemporary society" (Nylund, 2006, p. 31). By challenging whiteness in my research, I am making the invisible visible by identifying the missing gaps in knowledge in suicide, grief, and loss work. I seek to challenge the ways in which social, political, and structural forces are firmly entrenched in supporting and upholding whiteness as the superior identity upon which $t$ knowledge is validated.

The place from which power is exercised is often a hidden place, when we try to pin it down, the center always seems to be somewhere else. Yet we know that this phantom 
center, elusive as it is, exerts a real, undeniable power over the entire framework of our culture, and over the ways we think about it (Nakayama \& Krizek, 1995, p. 291)

The nature of this research clearly marks that there are subjugated knowledges that have been unheard and silenced. By centering the voices of a researcher of colour and participants of colour I am questioning and destabilizing whiteness as an apparatus to be exclusionary.

CRT and whiteness will inform my research and theory throughout the entire study, from the creation of my interview guide to the analysis of the findings. My intention is that by starting from a point in research that acknowledges that there is a difference in how grief, loss, and suicide is experienced the data will speak for itself to highlight the unique knowledge and understanding of South Asian people. In engaging in this work that is personal to me I am aware that I need to be conscious of how this is implicated in my work, as Fine (2006) notes, "[Being] 'too close to the topic', [one needs to] interrogate why they are studying what they study; what in their own biography, curiosity or sense of responsibility spurs the questions asked; whose perspectives will be privileged, negotiated, and/or silenced in their work" (p. 90). In acknowledging this I am stating that although I am part of the South Asian diaspora and have connections and ties to the culture, the South Asian identity is not fixed and so there will be shared understandings and meaning with my participants but there will also be vast differences in our culture. Nonetheless, it will be in these similarities and differences that I believe new knowledge can be derived. However, as herising (2005) notes, the politics of location state that simply situating oneself is never enough. Choosing to locate and situate oneself in research can have many meanings; it could be a political or personal stance, or it can be protective. 
Entwined with these meanings is also the power and privilege of being researcher. I have used critical reflexivity throughout the research process to interrogate my position, understandings, biases, beliefs, analysis, and relationship to the research. The self is viewed as a process, an ongoing, fluid construction whose identity is inextricably linked to social context and interpersonal interactions. The self construct is defined, at least in part, in dialogue with other people's understandings of who the self is (Kondrat, 1999, p. 459).

In this sense, my fluid constructions and beliefs of the South Asian identity will be transformed by my participants, and work to influence my inclusion and centering of diverse voices in this research.

Coming from a place where I am of South Asian decent and have experienced suicide of a loved one, I share a common experience with the participants of my study. My theoretical base is one that resonates with my life experience as well as my participants and is rooted in an ontological base that recognizes the multiplicity of all of our experiences that is centered by our South Asian cultural knowledge as well as the various identities and awareness that influence our uniqueness. 


\section{CHAPTER 3. LITERATURE REVIEW}

Dominant discourse on suicide, grief, and loss has predominantly been built upon the Western, colonial and medical approaches developed by white, middle-class people (Breen \& O'Connor, 2007; Ord, 2009; Valentine, 2006). The research has been based on a European or North American context and population, and has excluded the experiences of other cultures, or only represented an 'exotisized' interpretation which showcases the differences in the death or bereavement rituals of 'others' (Valentine, 2008). The majority of research also utilized an individualized focus common to Western understanding (Currer, 2007). European or Western based knowledge and research has been used as the marker for how people will work through these experiences; there is an underlying assumption that experiences of death, suicide, grief and loss equates to a universal experience. This type of discourse is not only Eurocentric but posits that the cultural views and practices of non-Western people are inferior to Western interpretations (Valentine, 2006). This is highly problematic as individuals who do not identify with Western models or approaches are forced to fit into prescribed models of care that are not based on their views. Those who are from a different culture and attach a particular cultural understanding and/or meaning to death, suicide, grief, and loss are at a disadvantage in that the majority of literature may not resonate with their conceptions. Though this lack of cultural knowledge in the area of suicide, grief and loss has been mentioned by numerous academics (Beautrais, 2004; 2005' Breen \& O’Connor, 2007; Cerel et al., 2009; Currer, 2007; Colucci \& Martin, 2007; Leach, 2006; Leenaars, 2008; McMenamy et al., 2008; Valentine, 2008), studies and literature with a cultural focus on suicide, grief and loss are limited.

Considering the diversity within countries like Canada, incorporating a broader understanding of these issues seems crucial to responding to and respecting the experiences of 
suicide, grief, and loss among culturally diverse people. Beyond this, looking at different cultural knowledge can expand the current knowledge base and practice of suicide, grief, and loss. What is important to remember however is that when exploring new constructions of suicide, grief, and loss, other ways of understanding and interpretation should be centered and located within culturally relevant knowledge that do not utilize comparisons to Western constructions as a basis. The goal would be to create a new expanded branch of suicide, grief and loss literature that bridges to Western knowledge but is legitimized and is able to stand on its own. As Beautrais (2005) notes,

The important question to ask when considering the examples of other cultural or ethnic groups is: What can be learnt from this example that could inform our thinking about [suicide, grief, and loss] rather than simply, What is different? Or what is the same? (p. 17).

Acknowledging that the universal experience may not exist but that other ways of knowing can and will contribute to all people is necessary so that those who have been isolated and excluded can share an equal space in knowledge production.

\section{Definition of South Asian}

The South Asian identity can encompass many different areas and regions of the world; most commonly South Asian refers to individuals whose own country of origin or family's country of origin is India, Pakistan, Bangladesh, Sri Lanka, Bhutan, and Nepal (Hsaio-Rei Hicks $\&$ Bhugra, 2003). Within these various countries there are also regional cultural differences that add to the multiplicity of the South Asian identity As Burman et al. (2002) notes, there are "multiple differences between the various South Asian communities in terms of culture, country of migration and religion" (p. 654); these cultural variations that also include language, add to 
the rich cultural diversity in those regions. Considering the vast migration that occurred from these numerous South Asian countries throughout the centuries (Statistics Canada, 2007), within my research I include people who identify as part of the South Asian diaspora. This can include individuals of South Asian descent from Africa, South America and the Caribbean, South East Asia, and throughout Western countries.

\section{Definition of Culture}

Culture can be defined in many different ways with many different meanings attached. Mato (2008) has defined culture as "related to both the production and the communication of meaning, which constitute significant aspects of all human practices” (p. 416). Joe et al. (2008) has defined culture as "the product of living together and creating traditions, norms, and values that manifest as a pattern in a specific group of people" (p. 359). Marecek (1998) has defined culture as "practices, materialism institutional, and discursive that organize social life and constitute individual subjectivity" (p. 69). Of all the definitions, the one that spoke to me the most was from Colucci and Martin (2007).

Culture is a complex topic and there is no perfect way to study it. We may think of it in a similar way to how we think of spirit: we have it, we were born with it, we feel it in almost all of our thoughts and acts, but we are not able to grasp it. But, if it is our intention to better understand suicide, and in particular to shed light on the impact of culture and ethnicity on suicide, we must stop researching exclusively percentages, rates, and odds ratios; risk factors and correlates. We must give back to culture, race, and ethnicity the complexity and importance they have in our inner lives, returning to beliefs, mental constructions, views, attitudes, mental processes and representations, values, 
motives, reasons, and meanings the importance they have in the life of a suicidal person. (p. 235)

The above quote stood out as it exemplifies why exploring culture and suicide must come from a place that is separate from traditional Western mainstream thought and approaches. It must destabilize what is considered the 'norm', and reexamine how culture is embedded in all social constructions of understandings of suicide to be able to honour the lives of people who have died by suicide. For my purposes, I define cultures as: where individuals in society come together to create and give meaning to shared belief systems, and values. Culture gives context to all individual, intrapersonal, and interpersonal relationships. It can be made up of rules and traditions that define cultural practices that individuals or communities abide by to help them identify with and feel that they belong. These rules and traditions however, are in constant flux and change and are at times open to intermingle with other cultures to create new meanings and identities, similar to what can happen with immigrants and second generation Canadians who may have accepted a multiplicity of culture. This definition of culture is also grounded in an awareness that culture can be racialized, exoticized, and political. It is this nuanced definition that will guide the research study and allow for an elaborate mixing and understanding of the fluidity of culture.

\section{Suicide and Culture}

One of the difficulties in situating a death from suicide comes from not being able to confirm whether a death was intentional or accidental. Furthermore, suicide and suicidal behaviours are socially constructed and often vary from culture to culture (Lester, 2008). The meaning attached to suicide and suicidal behaviour also continually shifts with the current social and political landscape; for example, although most people in Western society no longer consider 
suicide a crime or a sin, the pathologizing of suicide and suicidal behaviour remains common (Marsh, 2010). There are multiple definitions of suicide from various authors. Leach (2006) has defined suicide as "an intentional, self-inflicted act that results in death" (p. 8). Shneidman (1985) as cited in Leenaars (2008) stated, "Currently in the Western world, suicide is a conscious act of self induced annihilation, but best understood as a multidimensional malaise in a needful individual who defines an issue for which suicide is perceived as the best solution" (p. 24). Though all of the above definitions are based on Western knowledge and research of suicide and suicidal behaviour, they are relevant to the research because these discourses are part of the Western cultural constructions of suicide. I would have liked to include definitions from other cultures, however, the majority of the research was from a Western perspective, even where the research focus was about other cultures. This could be seen as a direct result of how colonialism has co-opted the language and research of other cultures; instead of valuing knowledge from one's own cultures, Western knowledge and practices has been positioned as the highest standard.

Historically, suicide has been cited in Western texts for many centuries; it has been found within Greek and Roman literature, biblical text, and even in Shakespeare's works. The meanings behind these terms have also shifted with time. As Marsh (2010) notes, early Roman society did not identify self-killings as rooted or based in an individuals' psychopathology; rather, it looked at suicide from a social level that was discussed publicly. This differs from modern suicidology research which is grounded in the study of psychiatry, psychology, and biology. This shifting of meaning continued throughout the centuries as Christian values began to influence the connection and power an individual had over oneself, wherein God became the moral marker; a person choosing to take their own life was seen as committing a sin and a crime 
Marsh (2010). This explanation of suicide as a crime and/or sin is still seen today in many different cultures and religions, and can result in suicide stigma where families may feel isolated or embarrassed to express the real cause of death to others (Joe et al., 2008).

During the $18^{\text {th }}$ century a French physician named Merian first described suicide and suicidal behaviour as we have come to understand it today in the Western world, when he stated that suicide and suicidal behaviour resulted from a mental disorder (Leach, 2006). From this point on, suicide and suicidal behaviour has been discussed from a medical perspective "almost solely in relation to notions of illness, diagnosis, treatment, prevention" (Marsh, 2010, p. 72). Though there were some exception to this as noted in Marsh (2010), such as Emile Durkheim's work on suicide in 1897 that looked at the sociocultural reasoning behind suicide, the majority of work from the $18^{\text {th }}$ century to present has been formed on a basis of individual mental defect, medical, psychological, and biological dysfunction, and theories of mental illness. Furthermore, there has been a discursive move that has shaped suicide as a tragic event, whereby there is no positive spectrum to place suicide in, it is only seen and understood as a negative experience, In the modern world, suicide is a grim business. It is understood primarily as an act arising out of intense, morbid, and pathological states of mind, representative of the furthest extreme of human misery. It is above all an isolated act, isolated not only in the sense that suicides of the modern era tend to seclude themselves from other before attempting their final act, but in the sense that suicide is held by modern writers to express a sense of personal alienation so complete that others cannot conceptualize [it]. (Hill ,2004, as cited in Marsh, 2010, p.80) Many may cite the medicalization of suicide as problematic since the medical community has disenfranchised people of various cultures and races for generations. This Western 
interpretation is applied to people from all cultures whether their own cultures value or view suicide in the same way; "Although White middle-income people constitute only $5 \%$ of the world's population, nearly all approaches to suicide assessment and intervention derive from the assumptions of, and research upon, this restricted segment of humanity" (Neimeyer, 2007 as cited in Leong \& Leach, 2008, p. ix). In recent years, suicidology researchers have come to the awareness that looking at suicide from multiple worldviews is not only appropriate but also needed within the field. Culture up until now has never been considered a primary factor when looking at suicide (Leong \& Leach, 2008). This becomes an issue when we see that Western models and understandings may not be sufficient to understand the unique dynamics of suicide (and grief and loss) in other cultures (Leenaars, 2008). This preoccupation with an individual's pathology and the tragedy of suicide may be at odds with how other cultures view and interpret death and suicide. This lack of understanding could constrain how family members bereaved by suicide are able to follow a path or journey after suicide of a loved one that is relevant and meaningful to them. Although some authors have moved towards including culture when discussing suicide, the literature remains sparse.

Suicidology has been growing as a field of study, though culture has only recently been included in the discussion and research as a vital component. Numerous studies have pointed to the benefit of including culture (Beautrais, 2004; Breen \& O’Connor, 2007; Colucci \& Martin, 2007; Cerel et al., 2009; Leong \& Leach, 2008; Leach, 2006; McMenamy et al., 2008). Up until now the "Empirical literature on cultural influences on suicide is modest" (Leach, 2006, p. 2). The little research there has been has pointed to the relevance of taking culture into account when looking at suicide prevention, intervention, coping mechanisms and risk/protective factors (Joe et al., p. 359). What remains as an issue though is that while there is a call for studies that 
bring in cultural knowledge, the epistemology developed is one that adds to and reinforces a Western understanding of suicide. The knowledge created does not centre other views as valid; rather, it places cultural as another variable that should be considered similar to gender, race, or sexual orientation.

From the literature reviewed, this 'adding-in' of culture seemed to be prevalent. Clarke et al. (2007) looked at pathways to suicidality across different ethnic groups. This study looked at various features such as socio-economic status, sense of community belonging, and disadvantages in education, income and occupational opportunities and how these contributed to suicidality of different ethnic groups. The results of the study centred on a comparison of the variables contributing to suicidal factors without an in-depth analysis of how the complexities of culture play out when looking at suicide or suicidal behaviour. There was no discussion whether the rates of people who speak of suicidal ideation may differ ethnically because of nuanced understandings of what suicide is or how it interpreted by different cultures. There was also no mention of how racism may affect or play into the variables they examined. In the same vein, Shiang (1998) conducted a comparison of completed suicides in San Fransisco from 1987-1996 among various racial backgrounds and used a comparison of Caucasian and Asian patterns of suicide. Shiang (1998) highlighted how culture impacted the study of suicide, by giving cultural context to how Western culture views suicide as an independent, autonomous act, while suicide in Asian cultures would be attached to a relationship context of meaning. She utilized a binary between both cultures that looked at the similarities and differences of Asian culture against that of the dominant Western Caucasian view of suicide. She did not shift her basis of understanding to one that centered an Asian worldview but rather sought how to 'add-in' cultural knowledge to Western practice. 
Looking at suicide from a cultural perspective is essential to understanding how different histories, politics, religion, and context mold how suicide and death are dealt with in a society. There can be no appropriate prevention or intervention strategies created if the complexities of a culture are not considered. Furthermore, prevention or interventions may not even be useful to some cultures where alternative methods for caring are employed. Delving into this rich cultural context, Marecek (1998) conducted a study in Sri Lanka, which has one of the highest rates of suicide in the world; she presented vignettes of Sri Lankan individuals who were contemplating suicide, and asked ordinary Sri Lankans what they thought of and how they would respond to this suicidal behaviour. Marecek (1998) noted that the discourse around suicide was situated very differently than in the west. Suicide was very rarely conceptualized as stemming from a mental health or psychological issue, rather, it was seen as an impulsive act, with $66 \%$ of the participants indicating they did not view the characters in the vignettes as mentally ill (Marecek, 1998). Marecek (1998) adds that the driving forces behind suicide were not individual pathology, misery, and isolation but social/interpersonal problems such as rage, the desire to get even, the wish to frighten or punish others, or the need to escape intense shame. The response to suicidal behaviour also highlighted that seeking psychiatric help or Western mental health services was not considered a useful response, with only $9 \%$ of respondents choosing that as an option. Medical help was defined as an interchangeable formal expert healing system that encompassed both Western and eastern medicine, prayer, astrological consults, religious and magic based rituals (Marecek, 1998). Though seeking medical help was considered useful by $64 \%$ of the participants, $27 \%$ also indicated the need of religious or spiritual practices as a source of assistance Marecek (1998). 
Similar to Marecek (1998), Vijayakumar (2008) found that "The crucial and causal role of depression in suicide has limited validity in India, whereas alcoholism emerges as a significant risk factor. Less than $10 \%$ of persons who had committed suicide had ever seen a mental health professional" (p. 1). Ettzersdorfer et al. (2008) studied attitudes towards suicide among medical students in India and Austria and found that mental disorder was not considered a significant factor in India. Suicide was considered as an impulsive and unworthy act.

The important thing to consider here is that the very basis of suicide in South Asian culture is found within a social conception. If suicide derives from a social root cause then addressing these issues would also mean taking a social rather than medical approach. It would also be important to then explore the historical, social and political issues that South Asian people are dealing with that cause disruption in their lives. As Leenaars et al. (2010) note, "India is a culture of collectivism, where the interpersonal realm is of central importance versus in a culture of individualism, such as America" (p. 428). This is why a simple comparison of culture as a variable lacks the analysis to create a broader interpretation of suicide.

An example of placing importance on cultural specific conditions that precipitate suicide is Chew-Graham et al. (2002). They conducted qualitative research in North West England involving four existing South Asian women's groups in the area; they held focus groups to discuss South Asian women community perspectives on perceptions of experiences of mental distress, attempted suicide and self-harm, and to comment on barriers preventing access to service provision. Their findings emphasize how systemic and cultural issues along with cultural pressure from within and outside the community were understood to be sources of mental distress, attempted suicide and self-harm behaviour. "The analysis highlighted the importance of understanding women's broader context and culture rather than focusing simply on attitudes to, 
and experiences of, the act of self-harm or suicide." (Chew-Graham, et al. 2002, p. 341). In a similar study, Hsiao- Rei Hicks and Bhugra (2003) examined the perceived causes of suicide attempts of 180 South Asian women in the United Kingdom, where South Asian women have high rates of suicide and attempted suicide. Socio-cultural specific factors were very significant in the suicidality of South Asian Women; issues such as family disputes over marriage and lifestyle, marital conflicts, in-law problems, unhappy arranged marriages, expectations of submission by women to men and elders, and culture conflicts were identified as primary issues and concerns Hsiao- Rei Hicks and Bhugra (2003). Another interesting finding was that depression once again was not considered the source of suicide or suicide attempts; instead, mental health issues were an outcome of the social problem, wherein once the social problem was considered to be resolved so too would any underlying depression Hsiao- Rei Hicks and Bhugra (2003). This understanding coincides with the cultural value placed on collectivism and rectifying social issues as the primary concern and not focusing on the mental health of the individual as that which needs mending.

Looking at suicide through a socio-cultural lens has its drawbacks as well. Bhardwaj (2001) emphasizes the slippery slope of pathologizing South Asian families as dysfunctional, attributing cultural features as homogenic, and embracing community-defined cultural beliefs that can subjugate certain South Asian identities within our own community. This can occur especially within closer knit communities and diasporic communities where individuals may be closely connected through family, religious, or social networks and looking to protect or uphold their cultural identity in the face racism, exclusion, and further marginalization. This protection of cultural identity can become problematic when harmful cultural expectations and norms are enforced on certain groups such as young South Asian woman to be a representation of cultural 
myths and stereotypes in the diaspora and can create "cultural conflict and identity flux between traditional Asian and Western cultures" for the individual (Hsaio Rei Hicks \& Bhugra, 2003, p. 460).

Burman et al. (2002) conducted interviews in Northwest England to investigate the perceptions of South Asian women's mental health needs in regard to suicide and self-harm. They spoke with managers in service provision, service providers, community groups, and South Asian woman survivors of attempted suicide and self-harm. They found that often culture overrides gender, which often suppresses how women are able to access help. They also found that service providers that are South Asian are at a disadvantage when mainstream services refer to them on the basis of culture. Burman et al. (2002) noted that these South Asian women feel they are not adequately equipped to handle particular issues such as suicide and self-harm but people are sent to their organization solely because of shared ethnicity. There were also issues of anonymity mentioned by the women in Burman et al.'s (2002) study, as well as lack of help actually received in community groups, gender subjugation, partnerships in name only, and contract work. As one manager stated, "White women can link into the service and systems better and the system understands them better. Services are there to meet the needs of mainstream and if you fall outside that it's hard to have your needs met" (Burman et al., 2002, p. $650)$.

Being South Asian myself, I can understand the hesitation of South Asian women seeking help with individuals who are part of your own community. However, what I found problematic in the findings was that South Asian practitioners felt that they were not well equipped to handle issues around suicide and suicidal behaviour. The article states that this is because "whatever training they [South Asian and Black practitioners] have had will have been structured according 
to available disciplinary models of theory and professional practice whose relevance in terms of gender and cultural issues has largely yet to be re-evaluated" (Burman et al., 2002, p.658). Here we see again another drawback of having suicide and suicidal behaviour being couched in terms of pathology rather than a South Asian worldview. Having said this, the article also did note, The picture emerging from the survivor interviews and confirmed by previous Britishbased work (Pembroke, 1994; Spandler, 1996; Yazdani, 1998) is that attempted suicide/self-harm is often a response to oppression based on racialized, gendered and classed experiences including sexual abuse, domestic violence, racial harassment and immigration (Burman et al., 2002, p. 651).

Another article that took issue with adopting a cultural view of suicide was Takahashi (2007). At the time the article was written, Takahashi was a practicing psychiatrist, and he felt that there has actually been too much of an emphasis on culture and suicide. He took issue with how cultural misconceptions increase prejudice and reinforced generalizations. Specifically, he spoke of the myth that suicide in Japan is permissible while in fact there is much stigma surrounding suicide that make people reluctant to access help in regards to mental health issues. There can be life-long stigma for surviving family members who have experienced suicide of a loved one.

The fine line that you walk when utilizing culture as the primary focus of inquiry is that it can be very easy to essentialize community identities or place too much of an emphasis on cultures so that other issues become hidden. The goal should be to bring forward a worldview that connects cultural viewpoints, histories, and traditions while still remaining holistic to the overall needs of a person. The benefits of developing knowledge from a cultural basis of understanding will be that strategies that derive from this type of research will speak to culturally 
diverse people in a way that Western knowledge has not. Though this study may not be relevant to all cultures, doing research for groups that have been missing in suicide research can open the door for more people who have been touched by suicide to come forward and shed light on how there are many different ways to live with suicide of a loved one.

\section{Culture and Grief/Loss/Bereavement}

Experiences of grief and loss are fairly common after death of a beloved family member. However, much like suicide research, grief and loss work has remained in the realm of dominant Western knowledge, focused on a Eurocentric worldview (Currer, 2007). Here, once again we see that culture has not been included in a meaningful way so that the bereavement needs of culturally diverse people have not been taken into account. "While cultural and religious beliefs may influence bereavement and responses to suicide, there are no studies which examine the unique needs for support of various cultural or religious groups or which compare bereavement after suicide across cultures" (Beautrais, 2004, p. 274). What this dearth in information translates to is a lack of awareness and comprehension of how culturally diverse people survive and journey through the aftermath of suicide of a loved one.

Being that grief and loss work has predominantly been situated in Western knowledge, I will begin with the Western conceptualization of grief and loss. Grief and loss can be defined and framed in a variety of ways. But in the last century it has been usually been used to describe the individual emotional and psychological process after death (Currer, 2007). There have been various definitions of what accounts for grief. Some suggest that it is a process we engage in to recover from a loss; it can be seen as a psychological period of adjustment to death and loss, or a reaction to death that creates symptoms and detrimental health consequences (Currer, 2007). The need to understand and define what grief and loss is and how it works has led to classifying, 
labeling, and medicalizing grief and loss. However, as Winkle (2001) suggests, it is a socially constructed term,

Grief is a socially established symbolic code, on the one hand allowing the communication of a loss, but at the same time restricting it as an emotional process of self-monitoring. Thus we face the existence of a social standard for the expression of mourning, based on individualization (p. 67).

In Western societies, there is an emphasis on this individualized concept of grief and loss. The majority of therapies and treatments have focused on this individualized approach. It has laid the groundwork for some very well-known models and responses. One very popular approach (Goldsworthy 2005) is that of Elizabeth Kubler Ross, who created the "Stages of Dying" from her work with terminally ill people in the United States. This model documented five stages that people progress through during grief: Denial, Anger, Bargaining, Depression, Acceptance. This model has been applied to all types of loss and grief, which was not the original intention of Ross (Currer, 2007). The intention of her work was "originally formulated to provide a framework in which to identify the stages or phases of dying that each person passed through in the dying trajectory" (Goldworthy 2005, p. 172). Another very influential work on grief was by John Bowlby who developed a model of "The Phases of Grief Work" in 1971. His original work stemmed from studying children who had been separated from their mothers. The four phases were: Numbness or Shock and Denial, Yearning and Protest, Despair, Gradual Recovery (Goldsworthy 2005).

Though these works and many that have been developed from these sources have been influential in grief work and assisting many people through their experiences of loss, they are also very problematic. The underlying message in the treatments and models is that there is a 
'right' and 'wrong' way to work through or experience grief, and alternatives to the methods are somehow abnormal. In recent years, we have seen that many scholars have criticized the application of this type of grief work and have recognized that grief is a highly complex process that is not linear, and could take many years to contend with (Sands \& Tennant, 2010). Scholars such as Arpana (2007), Lobar et al. (2006) and Schoulte (2011) also have noted that embedded in this work are assumptions of a universal application to all people. These models are mainly based on research conducted by white researchers on white middle class people. As mentioned above, it has only been very recently that cultural appropriate responses have been included in grief work. "It now seems that realities differ so greatly from one culture to another that it is misleading and egocentric to assume that Western concepts apply generally" (Rosenblatt, cited in Currer, 2007, p. 65). Given that it has been very recently that other perspectives have been included, the inclusion here to is more additive in nature. Other cultural ways of knowing in grief and loss are viewed again in a comparison to Western approaches or positioned below the scientific evidence-based practices in the west, as Summerfield (1999) cited in Drozdek and Wilson (2007) noted when speaking of his work on mental health programs in war affected areas. He found that all too often cultural ways of knowing are referred to as rituals and traditional, whereas Western approaches are seen as models and treatments Are the western approaches just well structured rituals in the western culture[?]... Western healers favor approaches that are evidence based, and often defined non western alternatives as mumbo-jumbo practices. At the same time, there have been almost no studies of non-western healing approaches. Opportunity to do scientific research is a privilege of rich societies, as most of the western societies are. Therefore, the exclusion of non evidence based approaches from those that should be applied in inter cultural 
trauma treatment does not seem appropriate. It reflects yet again the western scientific colonialism. (Summerfield ,1999, cited in Drozdek \& Wilson, p. 380).

Non-Western belief systems are continually placed in a binary relationship and seen as secondary to Western grief work, the knowledge that is the basis of Western grief and loss research may be completely at odds with cultural interpretations of what grief and loss are within other worldviews. For example, the very purpose of modern grief work is to help an individual sever an abnormal relationship with the deceased in order to come to terms with the loss, and move to or continue 'normal' functioning; there is rigidity to the process. This conflicts with non-Western views where suffering through grief and loss are a part of life and something to be welcomed, and where in many cultures having a continued bond with a deceased loved one is something that is expected and can actually assist someone through loss (Breen \& O'Connor, 2007; Drozdek \& Wilson, 2007). There is also less emphasis on the individualized nature of grief. Kasiram and Partab (2002) speak to community grieving and healing in South Africa, where communities come together to share grief in the spirit of 'ubuntu' translated as "We are who we are through others" (p. 39). Furthermore, the push for a medicalized approach to grief has turned journeying through grief into 'normal' and 'abnormal' pathology (Ord, 2009), which is not common to all cultures where grief can be looked at as in-balance in harmony, as in traditional Ayurvedic medicine that looks at the balance between mind, body, soul, society, and the cosmos (Drozdek \& Wilson, 2007). Grief also is considered to be rectified through rituals, prayers, and traditional religious ceremonies; there is an understanding of interconnectedness that is missing from Western concepts.

Working from a worldview, that attunes itself with cultural practices while validating alternative approaches, is needed to highlight the varied responses to death. More importantly, 
the current literature of grief must be examined and changed; a dominant discourse that is not reflective of people's needs is useless.

While bereavement is a universal phenomenon, the experience of grief is not. Grief is a unique experience that occurs within a historical, social, cultural, and political context, and our research endeavors need to recognize it as such. These contextual factors all affect an individual's grief experience and, as such, must not be omitted or viewed as extraneous variables. Instead, they need to be held in as much regard as the grief experience itself. (Breen \& O’Connor, 2007, p. 209)

For grief, loss, and bereavement work to speak to all people who have been affected by suicide, culture must be embedded and engaged in all aspects of accepted knowledge. How someone journeys through grief and loss should be respected and not pathologized as abnormal by a current knowledge system that does not allow for other ways of knowing. Dismissing other understandings of grief and loss that differ from Western discourse allows for culture to remain a variable. The myth of universality of current grief and loss needs to be shifted to ensure that supports and services are available to all survivors of suicide.

In summary suicide, grief, and loss has been centered and based on Western social constructions that have excluded research and knowledge that gives voice to racialized understandings of what suicide, grief, and loss is and how it is experienced. When looking at each area separately, suicide, grief and loss, and bereavement have utilized a Western perspective that posits that this ontological base is universal to all. The little work that has included culture and othered voices points to the need for more research and acknowledges that current literature cannot and does not depict accurate reflections and descriptions of knowledge of suicide, grief and loss in various cultures. Looking at my own research question of how South 
Asian families understand and interpret suicide and negotiate their personal experiences of loss and grief after suicide, I am attempting to shift the current space of accepted and validated knowledge while honoring my participants' stories through providing an outlet to speak to their subjective positions. 


\section{CHAPTER 4. METHODOLOGY}

Different from the generalizing nature of quantitative research, qualitative research methods may be more effective in placing interacting variables in context, more culturally congruent, and have the "potential of advancing knowledge and add much to the understanding of the relative roles of ethnicity, culture, socioeconomic, and other risk and protective factors for suicidal behaviour" (Joe at al., 2008, p, 358).With this in mind, I explored various qualitative approaches to research, and decides to use a narrative inquiry.

Narrative methodology has become very popular in the social sciences. Riessman and Quinney (2005) define personal narrative as "encompass[ing] long sections of talk - extended accounts of lives in context that develop over the course of single or multiple interviews" (p.394). It has the "capacity to recognize people's strength and engage people in active, meaning-making dialogues" (Fraser, 2004, p. 181). "Narratives are also social in the sense of reflecting broad social, cultural, ideological, and historical conditions in which they get told and get heard" (Chase, 2003, p.80). Through storytelling the narrator and researcher can organize these dialogues to find deeper meanings of events that can "contest oppressive and other imposed narrative[s]" of discourses (Humphrey, 2007, p. 16). There are a variety of ways of interpreting narrative but in its simplest conception it is a form of storytelling. "Storytelling is such an important activity because narratives help people to organize their experiences into meaningful episodes that call upon cultural modes of reasoning and representation" (Fraser, 2004, p.180).

I have chosen to utilize narrative methodology as how participants speak and share their stories will communicate to me how their self-identities have been shaped in the journey through their healing after suicide of a loved one. In choosing this as a methodology I was conscious of my own experiences and how sharing my story with others was difficult; and shame and stigma 
often stood in the way of me speaking about my loss. Nevertheless, even knowing that a storytelling approach may act as a barrier to finding participants, what motivated me to stick with this method was the feeling and the memories of the very first time I had told someone outside my immediate circle the truth about my father's death: the feeling was freedom. Though I clearly do not anticipate re-creating the same type of feeling within my participants, I am hoping that they too will grow from their telling, as I will when I share and reflect with them. "Benham (2007) reveals that the telling of memory can be both difficult and painful, it takes work to access these stories, but the story has the power to tell the truth about history" (Dunbar, 2008, p. 98).

Using a narrative methodology will also allow the participant to control how their story takes shape and is presented; in this way there is a shift in power whereby they will be able to show and share with me the self-identity that they feel comfortable with as they weave the story that is meaningful to them. "Narrative analysis focuses on the way individuals present their accounts of themselves and views self-narrations both as constructions and claims of identity" (Burck, 2005, p. 252). Furthermore, it "provides a way for both participant and researcher to link various contexts and discourses that shape personal lived experience" (Petty, 2000, p. 209), this is important since the participant and I will share common yet unique experiences. Not only will we share in our experiences of suicide of a loved one but we will also share a colonial history and a cultural awareness that will inform and shape the meanings we create.

The subject and the audience are not disconnected. They have similar lived experiences. Similar insights provide a window with which to share views without speaking, where a sound, seemingly inaudible to the unprepared ear, speaks volumes to a knowing listener, 
where the expressions on one's face tells the whole story or a simple nod says, "I know where you're coming from. (Dunbar, 2008, p. 90)

Analyzing from this perspective will highlight and showcase the varied and nuanced cultural interpretations of suicide, grief, and loss from a South Asian cultural perspective. In as much as there are moments of deep understanding, a narrative telling will also create space for the telling of cultural, familial, personal, and societal variances that may be hidden or overlooked in a study that did not employ both a critical race and narrative method. Narrative methodology and CRT will complement each other in that there is a giving back of power to the racialized participant who has the power and freedom to relay their story in any manner of their choosing which does not have to coincide with any specific Western model of communicating, "Narratives accounts are created in a sequence and consequence that is meaningful to the narrator events are selected, organized, connected, and evaluated" (Riessman \& Quinney, 2005, p. 394). Their frames of reference can come from their cultural base without feeling the need to explain or clarify. By working with me as a racilaized researcher, together we are working towards a centering of our worldview; this approach validates not only our experience but also our way of knowing and understanding the world.

In attempting to centre our world view through our shared stories and meaning makings, there are also pitfalls to be weary of as Willis and Saunders (2007) speak of when discussing Aboriginal led research.

While these (white) constructions of aboriginality are necessarily artificial, it is also a problem for aborigines to 'express' a true aboriginality independently of them. Shrinking from these definitions would tend to vacate a space in which the wheels of 'expression; 
would spin idly, if that is the theory of representation employed (Willis \& Saunders, 2007, p. 112).

In the same sense, trying to dissect or erase away a colonial history or the experience of being a second generation Canadian would be impossible and problematic. Instead of creating a fissure within the narrative there is the opportunity to create an altered understanding that can shift and ultimately create a new base of understanding of suicide, grief, and loss that incorporates the multiplicity of the participants. "We gain deeper understandings of the social resources that they draw on, resist, and transform as they tell their stories" (Chase, 2003, p.81).

Utilizing a narrative qualitative methodology will enable the participants to share their stories. Linking the various contexts and discourses that shape their experience, participants may then be able to "re-envision the 'self' after a loved one's suicide" (Petty, 2000, p. 209). In allowing space for participants to share their particular experiences this again centers the racialized voice that has been missing in suicide, grief, and loss work. This revisioning of self can also lead to a more nuanced cultural awareness and understanding that accentuates the multilayered positionality of the South Asian identity.

From the literature review it is very clear the culture has largely been ignored and devalued in suicide, grief and loss. By moving beyond an essentialized view of how suicide, grief and loss is experienced, new cultural strategies of responses, including developing strength and resilience, can be explored. This can only enhance current literature since taking "past inequalities into account...[can] create an alternative research context where muted voices could be heard" (Riessman \& Quinney, 2005, p. 402).

Having experienced loss of a loved one through suicide and then traveling through the years of not feeling like my experiences were understood or acknowledged has motivated me to 
engage in this research. By focusing in on critical race, I think this will create room for a different conception of suicide, grief and loss, or in the very least identify how South Asian individuals are in need of responses that speaks to them. It is my hope that unlike the little research that has been done I will be able to represent South Asian people in a way that gives them dignity but also sheds light on the very unique and culturally diverse characteristics of South Asian people. In centering and valuing this framework this research will be responding to the overwhelming scholars who have stated that culture must be explored further in suicide, grief and loss research. Khatidja (2003) notes that "The key to our arguments presented below has been our concern that this research does not itself perpetuate stereotypical constructions of South Asian women as passive victims, or of assumptions of South Asian communities as homogeneous along lines of gender, class and other oppressions" (p 34) this is what I would also hope for in my own research.

\section{My Story: Research Struggles}

Recruitment for this study was a difficult process as well as a new learning experience. The method of recruiting I used was snowball sampling. My initial plan was to contact work, educational, and personal contacts who could pass on information to interested participants. If interested participants would then contact me via phone or email; I would then personally contact individuals to give them more information about the study. I had started the recruitment phase by sending out a general email along with a research flyer to local South Asian organizations and grief and bereavement agencies. The only responses I received were that the flyer would be posted or passed on to appropriate individuals. Considering the time-sensitive nature of the research project I realized waiting for possible interviewees would not aid my search for participants. 
Moving forward I decided to add to my existing email, to indicate that I had my own relationship to loss of a loved one through suicide. As Kanuha (2000) notes, as a researcher from the South Asian community I chose my research based on my own personal connections to suicide.

The native researcher chooses not only a project in which she is deeply situated whether by geography, tradition, or simply "inside" experience, but also one in which she is invested in those factors and others as they inform the 'act' of research (Kanuha, 2000, p. 441).

Looking back, it was important for me as the researcher to show that I too shared a similar story and therefore similar fears to coming forward to share and 'out' myself within the community. Ensuring that I located myself in the research also meant that I had to engage and incorporate critical reflexivity into the research process. By being open and sharing my own story I needed to think about how my own experience influenced and shaped my thinking and understanding of the literature. I also needed to critically reflect on the impact of how sharing my own story of loss would impact my participants. Though I focused on the potential positive aspects of what sharing my story might have on my participants, I also needed to consider the challenges and drawbacks to this approach,

Being reflexive is a foundational aspect of both critical reflection and narrative research methods, and involves being aware of how we interpret actions, perceptions and responses (Fook, 2002; Redmond, 2006). In qualitative research, it is important to recognise the influence of the researcher and their positionality in all stages of the research, including data collection, data analysis and reporting the research (Hickson 2016, p. 386). 
Utilizing critical reflection also forced me to interrogate my own cultural understandings, interpretations, and biases. It was useful in the beginning stages of research as I was compelled to reflect on my research and recruitment struggles as a way to inform the research process.

I expanded my recruitment to include South Asian temples, masjids, women shelters, local community health centres, suicide survivors support services, more bereavement groups across the GTA, funeral homes that conducted support groups, victim services in the GTA, local South Asian TV shows, my family doctor who is South Asian, the Ontario Women's Health Network listserv and various contacts provided by my classmates and friends.

I finally received some responses from local bereavement organizations interested in my research; however, one bereavement support agency cited the lack of diversity in their clientele to help me with the outreach I needed. I was not surprised by this response considering that I myself had not reached out to mainstream services since I did not believe they could help me work through the complexity of suicide in a South Asian family. Nonetheless, this was still disappointing since I was completely unsure where else to reach out. By this point being completely behind in my timeline I honestly believed that I would not find any participants and possibly not be able to graduate from the MSW program. I also began to feel very isolated about being a South Asian person living through the experience of suicide; though I knew I was not the only South Asian person who had gone through this before, the lack of responses made me feel very alone in my experience.

After three months of sending out numerous emails on a daily basis I finally began to hear more responses. I received four responses from individuals who, though they did not fit the criteria for the study, wanted to help out with the research. This was uplifting to me since it at least demonstrated that there was some interest in my chosen topic. I emailed one respondent to 
clarify her interest in the study; her responses highlighted to me the type of cultural barriers that could be standing in my way of reaching South Asian people in particular as she immediately shared how her cultural value systems and culture influenced her thinking and therefore her understanding of suicide.

Her response solidified for me that my approach to research of suicide in South Asian culture had been so influenced by my own belief system and experience that I was limiting myself by expecting to find a South Asian person who replicated my feelings towards grieving through suicide. The entire time I was searching, thinking, and maybe even hoping that South Asian's somehow viewed suicide differently and were somehow more accepting of suicide than Western cultures. The motivation to find this type of data was based on my own personal narrative, yet I failed to realize as Martinez-Brawley (2001) pointed out, "The more culturally heterogeneous the context, the less replicable the phenomena" (p.280). Attempting research to find the answers or conclusion that I was searching for was not the way to share stories in order create awareness or change. I kept this in mind as I developed my interview questions; I hoped to create broad enough questions that created enough space for each participant to not feel limited in sharing their stories, while also having more direct guiding questions so we stayed focused on the subject. One of the broad questions I asked was

"How has the suicide of a loved one in your South Asian family impacted how you experience(d) grief and/or loss? The guiding questions were used to prompt and facilitate conversations with participants. Some of the guiding questions I used included, "Do you think your experience differs from someone who is not South Asian? -if yes, how?", Has your experience(s) of grief and loss been impacted by how your South Asian community understands/interprets suicide?", and "How did you or your family view suicide prior to the loss 
of a loved one? Has this view or understanding of suicide shifted or changed?" Being able to set aside what I personally thought the research would discover or unfold allowed me to be open and flexible to the many challenges that came my way along the process. "An insider's position is not necessarily an unchallengeble 'true' picture; it represents one possible perspective" (Hayano, cited in Kunha, 2000, p. 443); this was truly evident in every surprise that I encountered. My initial motivation to what I thought I would find ultimately highlighted the uniqueness of all our experiences within a South Asian context. It also allowed me to reflect on the mistakes I made during the recruitment process such as not reaching out in person to South Asian organizations, not staying consistent with recruiting and follow-up emails. In addition; it helped me accept that I would not find the exact research I was looking for, but regardless, researching suicide in South Asian Culture needed to be done and spoken about.

By leaving myself open to the possibilities I finally found two wonderful women as participants to my research. Though their stories did not quite match my participant criteria, by moving myself beyond doing research to validate my own experience, I had to be open to where the research would take me and not where I wanted it to go. Letting their stories and voice guide the research, the process, and the findings was still allowing for culture to be situated at the centre of research on suicide. 


\section{CHAPTER 5. FINDINGS}

My findings are based on two interviews that took place in June 2011. Although I struggled to find participants, I was able to gather data from both interviews that spoke to how the participants interpret and understand suicide, grief, and loss.

The first respondent was an immigrant Muslim woman in her late forties from Pakistan who had lived in India. She lived and worked in the Toronto area and was working at a shelter. She shared her story of grief and coping through numerous suicide attempts of her brother in-law and experiences of loss of friends and family who had suicided. She shared that part of her motivation to take part in the study was to educate the South Asian community on mental health and stigma.

The second respondent was originally assisting with recruitment; as I continued to stay connected with her to see if there were any interested participants who came forward she decided to take part in the study as she felt that given my research topic no South Asian people would come forward to share their insight due to stigma. She was an Christian Indian Immigrant who was working and residing in Toronto. She was working in a prominent position in an agency that was dedicated to serving the South Asian population in the GTA. She shared her experience of grief and loss of losing her nephew to suicide, as well as her experiences with other people in her life who had suicided over the years.

\section{Recruitment Challenges}

Recruitment for the study was challenging and I struggled to find participants even after posting my flyer widely for many months. Reflecting on the recruitment process, when I approached the recruitment I felt that posting the flyer would provide anonymity to participants who may be interested as they would be having a confidential interview at a location that was 
neutral, that would provide some privacy and protection. In hindsight, I overlooked or disregarded some key factors that may have had an impact on my recruitment. Although my research topic and question were clearly stated I was an unknown person to the South Asian community, and I had a Western last name that also did not show my direct link to the community. For South Asian people being able to place and identify where you are from, what community/what religion you belong to are important identifiers; with the last name Phillips, there is no way to connect me to the South Asian community.

Also, assuming that there would be a comfort level to communicate with me because there is anonymity was a mistake on my part. I might have had greater success attending a South Asian community centre and getting to know the clientele/community and proposing a group discussion instead of private interviews. However, due to time constraints and the limited scope of this research paper this was not possible.

Other key concerns in my recruitment was where I shared my flyer. I attempted to reach out to all South Asian community organizations and religious organizations including temples, masjids, and gurdwaras but again with no direct link into the community this was not very effective. I also reached out to mainstream death and bereavement groups but many identified that the clients from South Asian backgrounds were not there.

Both my respondents shared their thoughts of why I encountered challenges in their interviews. My first respondent mentioned that I may have struggled to find participants because of a fear of people disclosing information that could possible lead to police involvement and/or involvement with the Children's Aid Society. She also noted the subject matter is very private and potential participants may be fearful of having the information fall into the wrong hands, which she felt was especially true of recent immigrants. She also noted that a higher 
compensation value might assist with recruitment, although I recognize that doing so risks voluntary participation. My second participant felt that my poor recruitment was directly linked to the deep ingrained stigma attached to mental health and suicide.

\section{Key Themes}

Although I struggled to find participants, I was able to gather data from both interviews that spoke to how the participants interpret and understand suicide, grief, and loss. Through narrative analysis several themes were identified. The most prevalent theme was the role of culture and how it influenced how each respondent experienced and negotiated grief and loss, and coping. Both respondents spoke to cultural stigma, cultural reasons that influence suicide, and the impact of religion on how suicide is viewed. One respondent also shared how her personal experience of dealing with grief and loss were tied to her immigrant/settlement experience. Both participants also shared their personal views on how to combat the deep-rooted stigma of mental health and suicide and what they believe can be done through education and prevention to assist the South Asian community in creating a dialogue to address these issues in the future. Below I discuss each of these themes in detail.

Cultural stigma. One of the main themes identified in the data analysis was cultural stigma. This was described by both participants in various ways from stigma attached to mental health and suicide, impact of stigma to families and individuals, and generational stigma and shame associated to the family. Both participants shared how they believed stigma was tied to how South Asians experience, negotiate, and manage suicide and grief and loss.

When asked to describe what a South Asian worldview of suicide would be, Respondent Two stated that following, 
Like I said I, I think, you know, I think it's engrained somewhere in the psyche whether it comes down from generations of belief .. that this is a curse. That uh, and that curse is attached to stigma. You know, sometimes you feel families are cursed right? And that illness is actually a curse, it's, it's seen as an illness it's seen as a curse. It's seen as something that sets a family apart. I've seen families that in families where people have committed suicide um quite often, uh the family will be concerned because if there's a daughter in the family the daughter may not be able to get a good match, you know. So um, there is definitely a stigma attached to it that is not attached perhaps to the same degree within the North American mainstream community.

When Respondent One was asked the same question, her response was very similar to that of Respondent Two, noting A very bad thing... yea a taboo a stigma to the family shame to the family ....and uh they will never never even go you know to the family saying that oh your son did da da da and uh you must having a lot of troubles at home and all this type of stuff and then uh you have done such such things that's why it is you know it is bringing shame to your family like they will go I mean like years back to his family, I mean like saying that of your grandad did this and all this things and that is what is happening now. Like you are paying the price for what the generation olds have done...like you know you are paying the price of their own sins ...but I mean as a mainstream they don't they won't say ok he did this suicide because of maybe no food on the table...I mean like they will just say no its ok he was... and the people I think over here I mean they just take it as a grain of salt but uh in uh South Asian culture I mean it stay with the family all the while. It will not go away like that...it will harm the other individual I mean like if suppose... we had a 
younger sister in-law who wasn't married, she will never get married. Because no boy will come and propose to her...I mean like the family pay the price for it, it's not the individual thing they will think about it it is like generations after also that people will talk.

Here both respondents discuss the generational impact of suicide on the entire family, and identify that this burden of shame and stigma is carried by the family. In particular this seems to impact females in the family and future marriage prospects which in South Asian culture would create additional shame and stigma to the family to have unmarried females in the family. They both made the distinction of this view of stigma is different from a North American or Western cultural view of suicide.

Respondent One also spoke to this high level of stigma leading to the family wanting to hide or silence the issue in fear that others may come to know.

On the streets in India or in uh South Asian I mean nobody considers that I mean psychological traumas are as bad... I have seen that they want to abandon the people with mental illnesses... they will be considered just like garbage at home... I find for Asian people like they will think I mean he is a burden... Mental illness is considered a very bad thing or something it is taboo ... so it is always hidden that way... it's the family members it's the culture... they don't want to share it...shh don't talk about it he will not get a good girl ... it is better to be you know under the blanket in our own home.

Respondent Two also shared the same sentiment that the culture and stigma lead to a need to silence and hide due to the fear of stigma.

South Asians are extremely reluctant to share any issues related to suicide particularly in the family because of the stigma attached to mental health um you know in the 
historically you know , if someone had a mental health illness in the family it was kept well-hidden because it was associated with a family disorder you know a family mental health disorder that the family was not normal, in many respects so um the instance of one family member having an illness even associated with something like depression or you know, you would find that uh that family member would then be seen not just a family member but that stigma would be, uh sort of uh, it becomes, kinds of , it stigmatizes the entire family.

The idea of mental health and suicide stigma attaching to the entire family is mentioned by both; we can see how this is so engrained in the culture that even two women from two different religious and cultural groups (one from Pakistan and one from India) share a common understanding of how suicide is interpreted by the South Asian community. Both participants also mentioned that being part of the same community lead to community knowledge that would increase the stigma if a family had an individual who was experiencing mental health concerns; both noted that the word 'mad' was often used as a negative slur to describe these individuals. Respondent One also noted that the fear of people finding out prevented people from accessing help and using medication when prescribed.

If they go to a doctor [and] bring home medicine ... if you are living in a joined family and they see you eating certain type of tablet and then they say 'oh ok that sister in-law saw or that aunt saw' ...this is not good.

The concept of shame was also noted by both participants. The first respondent spoke throughout the interview of how shame and blame was another stigmatizing feature of mental health illness in the South Asian community that prevents people from reaching out and accessing support services: 
I know in South Asian thing I mean like even if you say that oh go for counselling or go for something like anything I mean it is think as a stigma attached to it as to why do we want to go and say something to that people... I mean if that leaks out then it's a it will becaome it will become bring shame to the family ... I mean like blame and shame. It is blame and shame game actually in South Asian thing. I mean the people will not forgive what happened year later also. Not forgive I mean they don't even forget.

Respondent Two spoke of shame but spoke to why participating in my research was her attempting to reach out to South Asian people to understand that sharing and expressing your story can help with grief, loss, and dealing with mental health,

[I want to] help people understand that there is no shame attached to it, that, in fact every human being, at some stage in their life, goes through that cycle. Maybe in lesser degree some and some others in, who are not, who are unable to let's say cope with it or manage it or who feel totally helpless then you know, that's a very small group, they end up taking their lives right? So, everybody I think what we have to acknowledge is that every one of us, copes with issues related to mental health, at some point or the other. And as South Asian immigrants, newcomers, refugees, um whatever we are in this country, the issue of moving from one country to another, the immigrant, immigrant settlement, issues, is in itself a huge, and traumatic experience because what you expect and what you discover, un through your time, is very different. There are no quick fixes.

The theme of cultural stigma was very evident in both interviews. Both respondents clearly identified that a South Asian view of mental health and suicide was directly linked to cultural concepts of stigma, family disorder, generational impacts, impacts on marriage, silence, and shame. Without having a strong understanding how nuanced and engrained the cultural 
stigma for suicide and mental health have on South Asian culture, it would be very difficult for mainstream social services to offer supports to clients.

Cultural reasons for suicide. During both interviews respondents repeatedly discussed cultural situations/reasons that South Asian people might consider suicide. Both participants mentioned school and academic pressure for young people and pressure to achieve from parents. Both participants seemed to believe that the pressure for academic achievement caused or directly motivated a young person to consider suicide.

It was a very early thing when I witness that boy died of you know can't stand not passing the exam and that time I was sixteen I was like thinking oh god why did he, why did he do that? He should of just come home ...He will get some beating of the parents but you know he would have and now the parents are crying why did you force him? So now parents are going to live that life all the while to their death. ...

I mean we consider we are forcing our children like I mean every parent you speak about it South Asian parents, how they will just incultivate [sic] in their children's mind that we have come to this Canada because of your studies because of your higher studies you have to get this studies well you have to either become a lawyer or a doctor or engineer here I mean every parent is like that I mean talk about it I know.” (Respondent One) It's a very very high level of suicides among young people who fail, who are not able to achieve what they have to, and uh I know I taught at uh a women's college and I remember when I, the first student, the first suicide in my class was this young woman. And I still see her face, I mean she was just, just the brightest young woman and she would fail in one subject and so she would fail and so she failed and then what she started doing, she wouldn't tell her parents that she had failed about whatever and I think she had all her 
hopes in becoming a doctor, you know, that's the goal right? Parents goal, our goal... But she had told her parents that she got her first class and I suppose when she really failed it was very difficult. And so she burnt herself." (Respondent Two)

It is interesting that both respondents can speak to multiple experiences of knowing several young people who have suicided; this may indicate a prevalence in cultural reasons for suicide. These two quotes seem to highlight the intense bond within South Asian families where children's identities seem to be closely linked to their parents in so that parents' beliefs, expectations, and norms are enacted on South Asian young people. There is no acknowledgment or separation of parents' goals and that of a young person.

Both respondents also noted that other reasons for suicide were attached to cultural norms and expectations of marriage or relationship issues. Respondent Two noted that "there were also young women who committed suicide because their parents were forcing them to get married somewhere else, and uh, there are many others you know, there was one who got pregnant and she couldn't talk about it." Respondent One similarly noted "Like suicide I mean people just think that 'ok (claps hands) this is the end you told me not to get married to this girl? I'm going to you know kill myself'. But that's not what it is when killing is very easy but how about I mean you're the one person only killed what about the circle?".

Both respondents spoke in much more detail in regard to academic reasoning than to issues or concerns of relationships or marriage, which as a South Asian I found surprising, since stories of people suiciding because of relationship issues were much more common to me. This again shows that culture is constantly in flux and there are no fixed meanings. What creates and upholds cultural values, beliefs, and systems are forever changing. The factors of academic achievement, parental pressure, and cultural norms and expectations around relationships that the 
two respondents noted are very much grounded in South Asian culture that in their experience can have a negative impact on young people and possibly contribute to why people consider suicide.

Religion and culture. Both participants spoke to how religion plays a role in how you experience grief and loss after suicide. Both viewed religion as a strong force within South Asian culture and though they had some similarities in experiencing stigma through religious death rites, they did have different positions on the role that religion or spirituality can have on grief, loss, and coping.

Death rites. Both respondents mentioned cultural restrictions for death rites in both their religions that furthered the burden of stigma on to families.

As a Muslim person ... in our books... it says that is person does suicide don't go to his uh funeral...so I think in our culture it is a main thing I mean bring a lot of religion into it than I mean thinking of it in a very ... open way and to sat that ok this is nothing to do with religion it is some kind of psychological thing or some kind of trauma which leads to this... so that's one of the thing I mean which differs from the South Asian to the mainstream... I mean we I mean a lot of I mean like religion to it... [By not attending funerals for people who have suicided] you are conveying... this is umm forbidden. (Respondent One)

Respondent Two also shared that there were some in her religious community that did not want her nephew buried by the church because he has suicided.

I remember there were people in the church who said, well we can't bury someone who has committed suicide. But then there was a minister who was very, uh, he said no he has to be buried as per our rights... He's already forgiven so we're nobody to judge. 
Though both are from two different religions the messaging behind performing death rites on a person who has suicided are very similar. In both religions death by suicide seems to be equally unacceptable and enforcing beliefs systems that suicide is forbidden is done though enacting control mechanisms on funeral rites. This is one area that may indicate a universality of how suicide is viewed across in more than one culture.

Respondent Two also noted that she felt that regardless of religion, how she felt South Asian people process grief and loss and utilize funerals to do this is different in comparison to other Canadians,

We clam it all together as if you know people come into this world and, ok they die and that's the end and you deal with it. And you see the funerals here [in Canada] and you know, in many cases you know there's a certain austerity about it and everything is done and you know even funerals are very well programmed and all. Um, but what I see in India is a funeral is meant for weeping, for crying, for hugging one another, for talking about it you know, maybe that's a way of expressing themselves in their grief maybe that's it... the people from South Asian community maybe that's the way they are able to uh deal with it right? And then after many of them might go into total retreat or to silence or um fast or do many things but certainly I think the Indian community is very spiritual by in large whatever the religion they are following, and it's that spirituality that help them in many instances to move forward.

In reflecting on death rites, both participants also are implicitly talking about how people negotiate loss and grief after suicide. While this will be taken up further in the discussion of the negotiation theme, it is worth noting here that both participants spoke about the importance of 
death rites and how they are engaged with differently in their religious communities, in response to death by suicide.

Spirituality: Advisors and alternatives to formal religion. Respondent One spoke at length about the roles that spiritual advisors or pseudo-spiritual people play in India and in Canada. For her, this has a negative impact on how mental health is dealt with in South Asian communities as she feels that these 'spiritual advisors' are business people who mislead people into believing that spiritual gimmicks and prayer can heal mental health concerns rather than medical interventions and clinical supports. This was something that she felt took advantage of families who were struggling and looking for answers to 'save' or 'cure' their sick family members. She also noted that this played into cultural stigma of mental health or suicide being attached to curses and witchcraft that needed to be exorcised or prayed out of a family,

She [mother in -law] used to think I mean like somebody has you know did any kind of witchcraft or something like that she will say that of my sin is never like that somebody has you know given him you know some kind of magic potion or something ... she used to go to our religious leaders and say that you know please pray for him ... and she'll bring home some of these things and we used to say that no, he's sick...nothing got to do with holy book... he's sick you have to accept that.

Respondent One felt that although she felt she understood why people would be attracted to seeking spiritual help outside of one's formal religion, she did not support it because she felt these spiritual advisors were fraudulent seeking to make money off desperate people.

You want I mean your people to be healed. You are weakened by all this things happening so you just grab anything which is little bit you know stronger whichever gives you and say that gives you support... you are just convincing yourself that of my 
son will get better... [you] have given up everything but you know this guy is telling you that he will get well so you just want to you know hold on to that leap of faith... but I mean nothing comes to you to question him.

She also spoke to how much these pseudo spiritual people, also known as spiritual advisors are a part of South Asian culture which she questions.

Lift any South Asian newspaper just pick it up and see that how many advertisements are there for ...If your family has been shunned or if your family has been in that witchcraft thing. I think every page ...you will find at least two or three advertisements... [even on tv] on the south Asian channel where you know this Baba is coming ... and will bless you and bless your house ... and if there is a bad spirit ...he can come What is all those things? I mean that is so much in culturate doesn't matter which religion you belong to if your ... South Asian.

Respondent Two believed there was a role for spirituality to play in healing and grief and loss but also believed in a blending of Western medical approaches and South Asian spirituality I think there has to be a fusion a coming together understanding that you know people from South Asian countries have a very long rich history of you know being able to provide some solutions whether it's in the form of yoga, whether it's in the form of that kind of spiritualism but that there's also umm you know we can't move away from the fact that you do need medical help and medical support and that we have to shift our mindset if we are looking at a global community right? Then we need to also look at how we are able to incorporate that global understanding so as not to force our views.

The role of culture religion and spirituality was highlighted by both participants but both viewed the use of religion in their experiences of grief and loss very differently. Respondent One 
based on her experiences with pseudo spiritual leaders and practices felt that there was no real replacement for medical intervention, whereas the second respondent firmly believed there was a space and a need to utilize the strength of South Asian spirituality coupled with other approaches to well-being.

Personal negotiation of grief and loss, and coping. In speaking about their personal stories of coping, grief and loss both participants came from different places of understanding that influenced how and what they shared. Respondent One spoke mainly of the several suicide attempts of her brother in law, he struggled through as many as 17 attempts but in the end, was able to receive the help he required and at the time of the interview was living a full life with a new family and career and according to Respondent One, he was very happy. This positive feeling may be why she did not focus on her personal experience of grief and loss but did speak to what she felt would help and assist others and spoke to what she felt was preventative.

Respondent Two shared her personal story of grief, loss, and coping after the death of her young nephew in India. She shared a much more detailed account of how she was impacted by her grief and loss. She also noted how she felt the immigrant experience hinders the ability to properly grieve.

Respondent One shared how she experienced negativity from people around her when advocating for her family to question the spiritual advisors who were assisting her brother in law with his mental health by providing him with religious trinkets and powders (that she felt was actually drugs such as valium). She spoke about how she coped with the pressure of being ostracized given her resistance to these practices. 
I [was] considered as blocked out like they will say that oh you are not even a Muslim and all these thing you are questioning us... I used to meditate a lot I started to you know read more of the religion ...that can help me...in a very positive way... I used to pray. Interesting to note that although she did not support her family seeking religious alternatives in dealing with her brother-in-law's mental health, she did turn to her own religion/spirituality for her own coping.

Respondent One also shared her advice to other people in the South Asian community who have experienced suicide of a family member.

Be open. Be open and...go to the right place to get the right information. I mean don't ... fall into all these stupid spiritual people...get seek help help from I mean like doctors or seek help social workers ...especially if you are in Canada I mean there is so much out there.

She also noted that more needs to be done to raise awareness in decreasing overall stigma. People in the South Asian community has to do a great job in saying relaying the message and only once people hear about all these type of issues they will come out...it is a job of a lot of community effort. It's not one person job because that stigma has to be removed from there and ...it has to be told told told... not only one social worker bringing up the subject to uh the light it is the full community like what our preachers doing? What are our social leaders doing? What are our religious leaders doing?

As noted above, it seems that the fact that her brother-in-law survived multiple suicide attempts, and not only survived but is not living a life where it appears his suicide risk has declined, has focused much of Respondent One's view of coping on recommendations. She is reflecting back 
on her own experiences by thinking about recommendations for others in terms of coping. This is very different than the ways that Respondent Two answered, when asked about coping.

Unlike Respondent One, Respondent Two spoke more directly to how she and her family personally negotiated their grief and loss. She spoke to her own experience after the death of her nephew and how her coping, grief and loss were impacted.

For me I know I felt that when I went to India, I completed all the formalities, I came back, and I got right into work. There has been no real grieving... There are certain things that the South Asian community in this country has, suppose learned to cope with which is, what other choice do I have? I have to survive in this country, my family has to survive, um I've lost a family member but then what am I to do about it, you know. So, the grieving is almost put back in the back burner but it comes back every and you know you go through the emotions of um sadness, of grief, of um anger, of anger at the person, of anger at the community, of anger at yourself, you feel a certain level of guilt, why couldn't I see more of this coming?

In this way, Respondent Two is talking about the challenges of trying to cope with this loss while in Canada, away from family and trying to maintain her responsibilities in Canada. She further shared a story of her Canadian coworker who experienced the loss of her son by suicide; she acknowledged that the experience was just as tragic as what she experienced but she noted that there were some differences in their experiences.

She had the opportunity to grieve...she had the ability to be with her family and to grieve with them but I can't imagine what loneliness she went through...if you [South Asian person] has a child that does that here, I mean you don't have a family support system here...half the family is back home and the rest is here, but the family back home, can 
you imagine they've never been able to see this child again? Because visa restrictions are so tough, it's hard to just walk away.

In addition to talking about coping in Canada, and the differences between her experience and that of her Canadian co-worker, Respondent Two also noted experiencing fear of receiving phone calls from back home after the death of her nephew, mentioning that she has experienced a lot of loss in her lifetime.

It's like you deal with so much death that at some point in life you just begin to accept this as a part of life. It's just the inevitable part of it but I know that for a long time I lived in this fear of what, whenever the phone rings from India, in early in the morning, I'm like, I hope this isn't bad news... and I've in talking with other South Asians I find that they live with the same fears as well. It's always that fear of what is this call going to mean?

This fear seems to be directly related to her experience of immigration and living in the diaspora. Though she speaks to having lived through many experiences of people dying, there might be a connection to her earlier remarks that living in Canada does not allow her to fully realize her grief and loss process and that underlying fear arises with each call.

Unlike Respondent One who focused on recommendations for coping, Respondent Two focused on her own personal view of suicide. Her own way of understanding suicide seemed to be an important part of her personal negotiation to assist her in coping and grieving her loss.

Sometimes suicide is, can happen on the spur of the moment and it can also be premeditated, right? With years of hopelessness. And I remember saying to my nephew and my brother in law. I said 'some people, no matter what, they may not be comfortable in this world. This is not the space maybe for them. And they feel that they're not, they're 
not able to adjust to this world and therefore they want to exit. They're not cowards like, we you know, most people often say oh this person commits suicide is a coward, it's not true at all. Someone who commits suicide has to have so much courage to take their own life, I mean it takes a lot of guts to do that. And I don't know how they do it because I for one could not'. But what I say is, you have to look at it in the context of some of us are able to deal with the struggles in our life and others feel' I'm tired of the battle. I'm tired of this, I don't belong in this place. I, I'm not I don't want to fight anymore. I just peacefully want to get out'. And so they, they create their own peace, I feel in, in doing what they do.

Having spoken about her own negotiations of loss, Respondent Two then shared how she has been using her own personal experience of loss in her own work to help destigmatize suicide and mental health. She also spoke to her feelings for guilt for not doing more to assist the South Asian community.

A lot [of the] time the work that you do is shaped by your own personal experiences and that's what creates the passion, un whether it's your family member or whether that it's somebody that you work with or whether it's you know a woman that you see you hear her story and then you feel this is just not right. You know that I feel that in many ways we are letting own our community and therefore the community needs to understand and to try to help them to get there in a way that is sensitive in a way that is...not overbearing. But to invite them into these conversations so that we de-stigmatize this whole issue.

She shared how her and her family have attempted re-frame their experience of grief in loss into a proactive approach to help others. 
I'm happy to say that well in our family at least, I know [my nephew's] father took a very proactive approach and we have been talking about, maybe when I retire setting up something to try to help people in [their community] at least to deal with it. In the work that I do I hear every aspect of our work is linked to some level of mental health support so that our clients can feel, we have wellness group, a group for women who have gone through abuse but also face depression and some of them have been, have come out of it and other have us, to go through the ups and downs. But the network they have formed helps them to stay in touch and try to cope to some extent with isolation that they're not alone in this, so that in of itself is a help.

In this way, Respondent Two began thinking about what could be done to support other families as they go through the process of loss, grief and coping. In this way, both respondents are thinking about recommendations for service providers and others, as I discuss in the final theme. However, before moving to that final theme, I want to conclude this theme on negotiation with acknowledging the strengths that both participants discussed in terms of the coping process. As part of negotiating and coping with loss and grief, both respondents implicitly spoke to the value of family strength. They both experienced or lived in fear of experiencing judgement or stigma from outsiders, but their own immediate families where a source of strength and support. They both also touched on immediate family members being primary support to family members experiencing mental health concerns, although they also acknowledged that this can lead to increased guilt for not being able to prevent suicide.

Recommendations. An unexpected theme that arose in both interviews was recommendations from both participants in how to address education, awareness, and prevention 
in mental health and suicide in South Asian communities. Both discussed having a targeted approach to increase awareness and education of mental health concerns and available supports. I think the first thing is CMHA (Canadian Mental Health Association) ... I have read some Urdu pamphlet ... CMHA has to hold lot of workshops around South Asian people and then it has to come out that ...it's a disease it's not something like stigma ...something like that I think it is type of years of work they have to do it. (Respondent One)

I think we have difficulty in uh, in even sending some of our own clients [to mainstream services] but we send them nevertheless because we want to make sure that whatever services are provided are provided in a way where people understand the background, the community, the way in which ... South Asians have been socialized. Whether it's in this country or whether it's coming from that country to this country... There has been a move to start some of the culturally sensitive stuff and I'm not saying that ... we have to profile ourselves or put ourselves in a box not necessary but I think there has to be an understanding that people that come from other countries face issues related to unemployment huge unemployment issues which can give them a lot of insecurities in life. (Respondent Two)

Interestingly, it was Respondent Two that linked recommendations to issues of culture, in noting below the importance of an analysis of race and culture being necessary to do work in this field. I find this interesting, that Respondent One focused only on how others should cope, while Respondent Two focused on her own experiences of coping and how she draws on that to inform her own work in this field. I am not sure how to understand this distinction, although I wonder if it is connected to the fact that Respondent One's brother-in-law survived multiple suicide 
attempts or that Respondent Two focused on her own negotiations of grief before considering how to help others. This is an area that could have been explored further if I had more participants or if I had done more than one interview with the participants.

I feel there is no real anti-racism analysis attached to the way in which we provide counselling services to people with, whether it's mental health disorders or whether it's violence prevention, or whatever it is you know or whether it's women going through abuse and violence when we have to intervene there is no real anti-racist analysis attached to it, anti-oppression, anti-racist analysis attached to it.” (Respondent Two).

However, both participants did speak to the role that service providers can play in reaching out to South Asian communities.

Educated people who are in that field ...have to come out ...hold hands ...[in] one of our community centers...one Saturday ...call people to give lectures...if you can't help it at least you can hold the person hand and cry let him cry on your shoulder. (Respondent One)

I think it's very important to provide support, not just counselling but there has to be some form of therapy along with it because people who go through a family suicide often face a number of unanswered questions that can haunt them for a very long time. To be able to cope with that and continue life and living and all the things you have to do... In the South Asian community, I think we have to take this one step further and talk about it in small circles where we help our community understand that this can happen to anybody. It can happen to anyone at any time. (Respondent Two)

In another area of recommendation, Respondent One goes on to speak about the use of media and how best to utilize media to build awareness and to combat stigma, 
Ban the advertisements [for religious/spiritual advisors] big time big time...you know sometimes I get so mad about it, I just say you have left your country but you have... come to this country and you are bringing your own issues here again? ...you can't bring ...the same thing from there, if you wanted to you shouldn't have immigrated. Main media. I know there are a lot of services available but come out in the main media come out to the...one hour Omni news...put on advertisement in many languages...Punjabi, Gujarati, and Hindi...Tamil...Bring that to the living room of the people wo that whoever is watching even if it's a small child ... if he remembers ...he will come back to talk to you... getting into the schools, getting into the community, mosques, temples...when this awareness come then they know...there are services available free of charge to them. (Respondent One)

Respondent One describes her recommendation in reaching out through media to access the South Asian community. She identifies the need to reach out to the multilingual South Asian communities and also shares the importance of reaching out to people through South Asian television. I agree with her notion that bringing information into the comfort of a South Asian family home is a good tool to promote services and build awareness. I find her point that providing education from an early age can also act as a preventative measure is important to note.

\section{Conclusion}

Culture in all its various forms was the overarching backdrop to all my key findings. Most discussed was cultural stigma and how this influenced every aspect of how suicide, grief and loss, and mental health was understood and expressed in South Asian culture. Cultural reasons for suicide that emphasized academic and parental pressure was discussed. Religion and 
culture was another key theme that presented a commonality of how death rites were utilized to oppress and stigmatize, while also accentuating the different notions, roles, and use of religion in coping and grief and loss. Both respondents also shared their own personal stories of negotiating grief and loss and spoke to their personal recommendations to assist other South Asian people who have shared similar experiences, including ways to combat stigma through education, awareness, and prevention that incorporated culture as its base. In the next chapter, I will further analyze the findings in the hope of challenging and interrogating normative dominant constructions that seek to silence the findings of my participants. 


\section{CHAPTER 6. DISCUSSION}

In this chapter, I will discuss limitations and strengths of the study followed by an indepth discussion of key themes of the findings. I will follow this with a brief discussion on the implication of this research on anti-oppressive practice and implication on future research in these areas.

\section{Limitations and Strengths}

In considering the limitations of this research study, the small sample size of two participants inhibits the findings being transferred to a wider population; additionally, the qualitative design means the findings cannot be applied to and generalized to all South Asian communities. However, the two participants were able to provide strong data that points to the need for more work to be completed in suicide, grief and loss. More research needs to be completed that incorporates diverse perspectives. For example, we need more literature to highlight that South Asians have strong cultural ties through a long rich history but as any other cultural group, there also are deep divisions, tensions, nuances that demand a non-essentialized interrogation of any research that speaks to the South Asian identity.

\section{Discussion of Key Themes}

In analyzing the data several themes were identified. Culture was an overarching theme that seemed to permeate every other theme in some way. Following the same process as in the Findings chapter, themes that will be discussed here are cultural stigma, cultural reasons for suicide, culture and religion, personal negotiation of grief and loss, and coping, and recommendations. I examine each of these themes in reference to current literature and my theoretical framework of critical race theory and whiteness. 
Cultural stigma. Cultural stigma was a prevalent theme throughout both interviews. Despite the varied positionality of the two participants there were many similarities in how stigma was seen, feared, and felt when discussing suicide and mental health. This suggests that there might be some notions of a universal experience of how South Asian families and individuals experience or negotiate mental health concerns, suicide and suicide attempts, and grief and loss. However, this possibly universal experience is clearly situated and grounded in a South Asian cultural worldview. Though the sample is small the similarities are striking which in the very least highlight the need for further research to be completed on South Asian identity and mental health, suicide, and grief and loss.

This finding coincides with the current literature in suicide, grief, loss, and bereavement that found that more work needs to be done to include and centre culture as the basis of epistemology in these fields; "research on the color and culture line has questioned, challenged, problematized, and disrupted dominant and hegemonic notions of what is categorized, conceptualized, and accepted as "normal" (Milner IV, 2007, p. 389). The literature review spoke to the privileging of Western concepts and understanding as the unspoken normative that suicide, grief and loss research has typically been based on. Findings from the participants demonstrate the depth to which South Asian cultural understandings influence the experience of the loss of a loved one to suicide and reinforces the need for research about these experiences, rather than assuming current knowledge is sufficient. Working towards disrupting the current knowledge base would mean "denaturalize[ing] the idea of whiteness as the privileged place of racial normativity" (Nylund, 2006, p. 31), and thus recognizing that there are many experiences that are not the same as the 'mainstream/white' approaches suggested in the literature. 
While beyond the scope of this study, considering the deeply politized tradition and history of South Asian culture (Kulke and Ruthermund 2004), unearthing the root causes of stigma is research that is needed. Notions of generational stigma and family mental health disorder/stigma are important findings that could inform practice and services to ensure that those whose experiences do not fit with mainstream/white approaches to helping are receiving equal benefits of supports that are available to mainstream service users. Furthermore, without the knowledge that these very specific cultural understandings of stigma exist, how would a service provider assist a family moving though mental health, grief and loss. This has real implications for practice as "therapists are inevitably engaged in a political activity in the sense that they must continually challenge the techniques that subjugate persons to a dominant ideology" (Nylund, 2006, p. 36). Incorporating and building on generational and family stigma is one way that new research can revitalize this area of knowledge and centre culture as beyond an essentialized variable.

Cultural reasons for suicide. In both interviews participants spoke to South Asian cultural norms that drove young people to commit suicide. Areas of academic achievement, pressure from parents, and failing to achieve in academics were noted as the underlying factors of suicide in young people. There was no mention of underlying mental health concerns; instead, the respondents drew a direct link from young people not being able to achieve a certain level of academic status and therefore not meet parental expectation. As Shiang (1998) noted in her research most Asian communities and cultures are structured around a collective understanding versus the individual. This includes an understanding of expectations from community that young people will succeed in education and employment, which can be tied to parents relying on their children to fulfill the parents' own dreams of success (Bhattacharya \& Schoppelrey, 2004). 
One can see how the many examples of young people suiciding due to academic and parental pressure relates to South Asian family structure and collective community pressure.

An important element of collective cultures is the preservation of group solidarity. Yamashiro and Matsuoka $(1997,182)$ stipulate that collective cultures often reinforce norms through various social control mechanisms including surveillance and the shaming of refractory behaviors. Non-compliance of critical elements of the culture, such as educational achievement is subjected to dishonour and loss of prestige of the family. This is effective in collective cultures because the behaviour of one person reflects on the entire group or family system. It places social pressure on all members of the family to act in culturally appropriate ways, and to conform to and fulfill role prescriptions. (Sommerville \& Robinson, 2016, p. 103)

This seems to support findings from Chew-Graham et al. (2002) and Hsiao- Rei Hicks and Bhugra (2003) that often the precipitating factors for suicide and self-harming behaviour sits outside of medicalized pathology, that culture can often override any other marker or identity construction such as gender. Given this finding it is important to explore how this then expands to affect the diasporic South Asian community as well as young people in South Asian countries.

More importantly, as South Asians in Western countries have been viewed as a, "model minority refer[ing] to visible minority populations whose members are more likely to achieve higher success than other minority groups, especially in economic advantage, academic success, and family stability," (Sommerville \& Robinson, 2016, p. 101). Collective community expectations of success fit this model minority theory, wherein South Asians want to be seen as successful in their new country. However, drawing from critical race theory and whiteness, we can see how the notion of model minority perpetuates whiteness, with Western markers of 
success; a racialized person, or "minority" member of society, is deemed successful when they model white success - that the model minority theory is in itself a myth perpetuated by whiteness (Chou \& Feagin, 2015). One needs to be careful of utilizing stereotypical, racist assumptions in addressing these concerns in practice.

Additionally, despite the appearance of cultural norms, belief systems, and traditions as being universal across South Asian culture, one must recognize that how the issues of academic stress, pressure, and parental expectation are internalized and enacted will vary individually. What is important is that practitioners are mindful and aware that though certain cultural practices or norms may exist, while assisting clients navigate these areas of concern, they need to be careful that they are not supporting and upholding belief systems that further subjugate South Asian identities. As Bhardwaj (2001) noted, By pathologizing salient community features such as family structures, we have been drawn into elitist cultural constructions that do more to exoticize and oppress than to liberate... In addition to pathology, a further inherent danger in external definitions are those of cultural homogeneity... most significant in socio-cultural analysis is the empathy towards and application of, community-defined measures... They embody enormously powerful cultural judgements with the power to include and ostracize. Such cultural beliefs can be described as a double-edge sword, they persistently legitimize gender violence and oppression and further silence women from being able to discuss, seek support or challenge such oppressions, for in doing so it is deemed as bringing further shame and dishonour to the family and community (p. 55).

This is a fine line for practitioners to balance with their clients but a racially politized response is needed to speak to the full spectrum of the South Asian identity that is subjugated but also seeks 
to subjugate through cultural belief systems. As Joe et al. 2008 indicate, more needs to be done to understand suicidology from a cultural perspective. Without reframing and creating space for new knowledge to exist in these areas we will continue to leave racialized groups outside of appropriate interventions.

Critical race theory speaks to this devaluing of other unique voices as a gap in knowledge that serves a purpose to uphold the status-quo,

Viewing racial disparities in access to mental health treatment through the CRT framework suggests the unique voice and experiences of people of color have been ignored and undervalued... Most mental health interventions are designed and tested via university or lab settings where most participants are upper- and middle-class Whites... The CRT lens suggests that the mental health system has not adequately solicited or incorporated the authentic voice of people of color, and that to develop and deliver acceptable, effective mental health treatment, it is imperative to listen to and understand their perceptions... treatment acknowledging and addressing the negative relationship between discrimination and mental health has not been prioritized because it would not benefit Whites. It may even force Whites to acknowledge that racism and their own privilege likely contribute to psychiatric distress (Kolivoski et al., 2014, p. 274). If academic stress and parental pressure are specific suicide risk factors for South Asian young people, given the complexity of this issue more research is needed to create appropriate preventative measures. This is also true of other cultural reasons for suicide that the participants spoke to which included cultural norms and expectations on relationships and marriage.

Religion and culture. Religion was another area that was discussed by both participants. Respondents One and Two come from two different religious backgrounds of Islam and 
Christianity, but there are some similarities in that both come from two South Asian religions that are stepped in a rich tradition, and have a long existence within South East Asia (Kulke \& Ruthermund 2004). Although how they utilized religion and spirituality in their personal experiences differed, the role and impact of religion was polarizing. Both respondents spoke to the strong messaging from both their faiths when engaging in funeral rites. Disallowing funeral services to take place with proper rituals and attendance seemed to be a way to control and forbid suicide. But despite this, both spoke to how religion and spirituality also played pivotal roles in how they personally negotiated grief, loss, and coping.

Religions attempt to create a conception of existence ... in which death is incorporated as a meaningful element'”. Such statements suggest that the functions of religion during bereavement due to the suicide death of a loved one merits research attention... Evidence suggests that suicide-related bereavement is sufficiently unique to merit specific attention (Jordan, 2001) and yet, as reviewed above, we found only one published study and four dissertations that focused specifically on religion during suicide bereavement. We conclude that existing scientific knowledge concerning the function of religion during suicide bereavement is minimal (Vandecreek \& Mottram, 2009, p. 742).

As Vandecreek and Mottram (2009) note above, the role of religion in bereavement after suicide warrants attention; however, research is limited. What is more problematic is that with what research currently exists, the likelihood that it engages and centers Eastern religious as the base of research knowledge is highly unlikely. So how then do we incorporate, evaluate, and interrogate the role of religion for South Asians in grief, loss, and coping?

Social work has been working to include religion and spirituality in practice as it recognizes religion and spirituality as "sources of strengths of many marginalized populations, 
tapping into their wisdom, resilience, possibilities, and hope, as well as recognizing Indigenous and other non-Western modalities for social work practice." (Wong \& Vinsky, 2009, p. 1344). However, more must be done to include 'othered' voices in research when looking at the impact of religion on South Asian communities. This is especially important when we see that the positionality of Eastern religions in North America and how they have been commodified in the West.

Colonial authority is established by generating structures of thinking in binary opposition... if the racialized ethnic 'other' is religious and culturally bound by traditions and doctrines, the Western 'self' is spiritual, free and independent in their personal quest of the 'Ultimate'. The ordering of social relations between the 'spiritual' Western 'self' and the 'religious' ethnic 'other' is produced... many 'ethnic' religions from the East have been partialized and selectively re-packaged to serve the eclectic interests of Western 'spiritual consumers (Wong \& Vinsky, 2009, p.1353).

As the literature review noted Western notions and concepts are perpetually utilized to serve as the normative base of suicide, grief, and loss research. Critical Race theory asks us to examine how and why South Asian religions and culture has been commodified and established as a binary to serve the privileged position of Western modalities and how through on-going resistance can we reframe what is valid knowledge.

Personal negotiation. Findings in this section were reflective of the fact that Respondent Two was speaking directly to the experience of negotiating personal grief and loss after the suicide of a loved one, whereas Respondent One had a family member who self-harmed but survived. It seems that the more personal reflection, and the deep impact of the death by suicide, rather than the suicide survival, fostered much more nuanced responses from Respondent Two. 
The response seemed more nuanced as she provided specific detail in how she felt, thought of, and processed her grief response; it was a very personal account. Overall, we learned that for a South Asian person many varying factors can contribute to grief, loss, and bereavement.

An important finding was the impact of the immigrant/settlement experience on Respondent Two's ability to grieve. This was not noted in the literature review. These findings speak to the need of incorporating South Asian identities and positionalities, histories, social, and political realities into suicide, grief and loss research. Critical race theory can provide a strong theoretical foundation for such research, meeting the need of culturally-specific research while also filling the theoretical void noted in the literature review.

Throughout her story, Respondent Two shared that the South Asian experience of immigration and resettlement can be a traumatic experience with many social impacts that can affect individuals and lead to depression and other mental health concerns. But how she articulated her stunted grieving was an unexpected aspect that I had not considered. Though she utilized a comparison to express her point she firmly grounded her voice as the central point of knowledge. As Reyes-Cruz (2008) notes,

Linda Tuhiwai Smith (1999/2005) has said that, decolonization . . does not mean and has not meant a total rejection of all theory or research or Western knowledge. Rather, it is about centering our concerns and world views and then coming to know and understand theory and research from our own perspectives and for our own purposes" (p. $654)$.

In this way, I do not suggest that we resist or abandon Western knowledge, but instead that we recognize knowledge equally from all worldviews. 
Of all the findings, this may be the most important as her experience situates herself and South Asian identity as the central focus of the grieving and loss experience. It is her othered, racially politized identity that positions her as unable to express, feel, or process her on-going emotions with the death of her nephew. As an immigrant woman in a new country she is not allowed or provided the "opportunity to grieve" as she states in her interview. She also shares her resulting fear of receiving a phone call from back home after the loss of her nephew which may also be connected to her experience of loss itself but also the inability to have the full opportunity to grieve with her immediate and extended family. It is by incorporating voices of the marginalized that we will be able to fully move towards unearthing more culturally relevant knowledge that can speak to different realities,

Race-based methodologies can be used to disassemble hegemonic knowledge and discourse (Cook, 2013) and to assemble racialized epistemologies, a system of knowing, that serves as counter knowledge and a liberating tool for marginalized groups. This type of knowledge production can transcend superficial descriptions and decontextualized facts and produce substantive descriptions and contextual text (Rocco et al. 2014, p. 466). Further research in this area is necessary to understand the impact of immigration/settlement on grieving the loss of a family member, as well as understanding the role of racism and other structural oppression on the process of grieving and loss, which I discuss further below.

\section{Implications}

Looking back to my original research question, "How has the suicide of a loved one in your South Asian family impacted how you experience(d) grief and/or loss?”, I wonder how fully I have been able to answer it. My findings barely scratch the surface of the possibilities of the multiple ways in which South Asians experience and understand suicide or grief and loss. 
Initially as I struggled to find participants I was told by those supporting me that this in itself spoke to why this research was necessary, although this did not bring me any comfort in the process. I was also very distraught that I had only found one participant who was able to directly speak to the loss of a family member through suicide whereas the other was speaking of a family member who survived suicide.

What I was overlooking was the prevalence of multiple experiences with other friends and family who had suicided and how this was a common experience to many South Asian people. As well, even with only two participants the amount of knowledge and experience with suicide, grief and loss was strong and I was lucky to have found two very open participants who were willing to share their stories with such honesty.

There is no clear answer to my original research question, although perhaps the answer is that the impact of grief and loss after suicide is individual, cultural, racialized, political, collective, and unique. What was evident was that there is valid knowledge that is missing and discounted from the sphere of suicide, grief and loss discourse. The findings speak to the fact that every cultural group will have their own experience that will be influenced by their own rich history and tradition. For South Asians exploring the impact of stigma is an area that needs to be interrogated further.

Also of note were the recommendations that both participants spoke to during their interviews, finding culturally responsive preventions, solutions, and education can and will come from South Asian people themselves. The issue that remains is how do we continue to push for the legitimization of gaining knowledge from racially othered cultural groups,

Cook (2013) asserted that all social science research tells a story and that the role of storytelling in CRT is to actively push back against the dominant story. The dominant 
story plays out in research in two ways: (a) Whiteness is assumed to be the norm while other experiences are outliers and (b) Whites speak for other groups and tell their stories according to a dominant narrative. Storytelling/voice can be fostered by merely including people of color and other minority voices in all research designs. Instead of designing research projects where race is demographic information, design studies where the phenomenon of interest is examined according to its relationship or impact on people from different racial groups remembering that White is a racial group too (Rocco et al., 2014, p. 466).

This again speaks to the literature that a centering of epistemology is needed and the 'adding in' of culture as a variable to research must be discontinued. More research is needed that is developed by people of colour and includes the voices and stories of people of colour. Critical race theory and critical whiteness points to the need to push for transformative action and change to ensure that the there is no normative dominant discourse unless it includes all positions and identities. But more importantly the experiences of all need to matter and be looked at as valid sites of knowledge that more research can built and developed on,

Let me be clear. I'm not talking about collecting 'the other's' stories, amplifying their voices, analyzing their comings and goings, supporting our theories with the observations we make about their lives. What I'm talking about is grounding our theories, anchoring them, on the reflections nonacademics make about social life as they live it, elaborating theory with them instead of about them. The struggle for decolonizing knowledge needs to go beyond developing research projects from and with the historically marginalized to actually elaborate theory based on the reflections people make about social life. Doing so could open more spaces for colonial subjects anywhere: from within and outside 
academic circles, for those who maintain evident connections to their ancestral ways of knowing and those who cannot or simply do not make such claims. (Reyes-Cruz, 2008, p. 656)

As Reyes-Cruz notes, this would go beyond simplified notions of 'adding in' or using already marginalized voices in research to uphold privilege and whiteness. The goal of transformative anti-oppressive, anti-racist research needs to be this site of creating theory with and not about. As my participants noted solutions and I suggest knowledge, will come from the inclusion of South Asian people in research and research development.

Implications for anti-oppressive practice (AOP). This research has implications for AOP since deconstructing and engaging in decolonizing research is at the crux of AOP practice along with addressing inequalities, power dynamics, and questioning normative practices (Turney 1997). The missing voices that are ignored and furtherer subjugated by the privileging of certain knowledges is an area that AOP is continually situated to fight against. This process of decolonizing can disrupt whiteness in knowledge production, "defined as 'a form of hegemony that allows one group to use its power to dominate a group in a position of less power" (Sakamoto 2007, p. 108) and ensure that researchers and educators are questioning fixed belief systems that do not speak to all. As Srivastava (1996) notes,

Consciousness changing is not accomplished by new discourses replacing old ones. It is accomplished as a result of the contradictions in our positions, desires and practices and thus in our subjectivities - which result from the coexistence of the old and the new. Every relation and every practice to some extent articulates such contradictions and therefore is a site of potential change as much as it is a site of reproduction (p. 269). 
It is through this type of constant reorganizing of discourses, practice ideals, and values, that we are able to move beyond simplified constructions of race to enhance and reposition knowledge production in suicide, grief and loss work.

The finding of this research points to the need to further examine the role of various cultures as it seems there is new knowledge that has not been brought forth that can change current practice models for suicide, grief, and loss work, "Deconstructing the dominant discourse means bringing its oppressive underpinnings to light so that a counterdiscourse, one that critiques the ruling discourse and points the way toward more egalitarian social relations, practices, and processes, may be developed" (Larson, 2008, p. 47). AOP calls on workers to contribute to processes that disrupts inequalities in a way to move towards social justice, by demanding that all voices have the right to build and develop discourse and research methodologies that involve non-Westernized perspectives, As Smith (1999) states in relation to Indigenous research, "when indigenous peoples become the researchers and not merely the researched, the activity of research is transformed, questions are framed differently, priorities are ranked differently, problems are defined differently, and people participate on different terms (p. 193). This can also be applied to subjugated identity positions of South Asians and how by engaging in this research the participants and I are pushing the boundaries and allowing for our voices to fight normative ideologies.

On a micro level, this research has implication on AOP in how service providers engage and support South Asian clients who are in medical crisis, or struggling with coping, as well as in supporting families or individuals who self-harm or who have had someone suicide. Though limited in scope, the research here suggests that having experiences with family members who self-harm or die by suicide may be common to South Asian people. This coupled with the high 
level of stigma could lead to South Asians not reaching out to supports in fear of breaks in confidentiality that could lead to an 'outing' of their personal situation. AOP practitioners who are engaged in providing work that moves beyond cultural competence can play a role in addressing the gap in services by responding to the individual within a contextuality that acknowledges that South Asian people are exhibiting resistance just by accessing mainstream services given the level of risk to themselves. The use of cultural humility, which "involves seeking to understand individuals' identity-related experiences and how these are related to power imbalances at individual and institutional levels... by assuming an active role in challenging and mitigating identified power imbalances" (Charles et al., 2017, p.416), might be a useful AOP practice to assist practitioners in working with South Asian clients.

Another implication for AOP is the role that AOP educators and schools can play in encouraging people of colour like myself to engage in research. Throughout both my interviews my participants shared or passed some information on to me in a way that acknowledged a common landscape and understanding; even though I was a younger Canadian born second generation South Asian Indian woman, there were moments that they would allude to a common understanding just by the virtue that I was also South Asian. Things did not have to be explained in detail as they felt or made the assumption that as a fellow South Asian I knew how things operated or I understood some of the contextual history. Although it is problematic to essentialize our three identities, I do feel that this common shared space of understanding contributed to how open and comfortable to the interview process was, and speaks to the rich data I was able to obtain from only two interviews. 


\section{Future Research}

This was a very small focused research study however, there are several areas that could be explored further in research.

The difficulty in finding participants also speak to the greater need for more work to be done in this area since two participants were able to provide rich data that spoke to high levels of stigma that can act as a deterrent in reaching out to needed supports and services; to truly engage in preventative work for suicide and mental health for South Asian people more must be done to create safe spaces for people to come forward and share their experiences. Without further research in how to destabilize strongly entrenched views of stigma in suicide and mental health South Asians will continue to be on the periphery and not be able to connect to meaningful supports.

One area of future research could be that of exploring the comfort levels of multicultural agencies and organizations referring their clients to mainstream services. As Respondent Two noted in her interview, appropriate referrals are made to outside agencies however, there is a level of discomfort in doing so. I think exploring this space of discomfort is important as it could speak to the larger systemic barriers and oppression that is felt by these organizations.

Another area of future research possibilities is the need to further explore on a larger scale how South Asians experience grief and loss and the cultural aspects that hinder or assist in the grieving process. Specifically researching how the immigrant/settlement experience affects how an individual is able to cope with grief and loss would be invaluable.

Another area of future research could be exploring how South Asians actively resist the intense cultural stigma of mental health and suicide. The notions of generational stigma, family disorder stigma are strong forces that are utilized to control and subjugate South Asian however, 
we see through my two participants that there are those who are resisting these cultural dynamics to assist other South Asian people in coming forward. 


\section{CHAPTER 7. CONCLUSION}

Reflecting on this research my initial motivation was driven by my own personal experience of being South Asian and losing my father to suicide. My experience of moving through grief and loss both initially and over the years seemed to be heavily influenced by my South Asian identity and culture. The available research in the areas of grief, loss, and suicide did not seem to capture my reality nor understand the complexity that culture can create when dealing with these ideologies that are firmly placed and formed in a long history of tradition, beliefs, customs, social and political histories. As well, the literature that was available that included culture was problematic as it acknowledged the lack of research and literature but where culture was included it was situated as a binary to Western understandings.

The aim of my research was to create space where unheard and hidden voices could share their important knowledge and contribute to current literature to include and centre their understandings of grief and loss after suicide. Although this research was extremely limited in scope and size, my hope was that there would be some important point in the data that would highlight why more research in this area was needed.

My findings do suggest that the how South Asian people experience grief and loss after suicide or self- harming behavior is linked to cultural definitions and meanings and cannot simply be seen as separate dichotomies; they are inextricably linked to culture in ways that can assist families in dealing with loss such as your immediate family being of great support or for some culture can be used to restrict and restrain grief due to cultural stigma and beliefs that can hinder how South Asian people access resources and support. As well, culture and race can play a role in how grief and loss is impacted especially for immigrant families. 
What is important to future research in this area is to ensure that South Asian identities and experiences are centered and seen as valid locations for knowledge and not essentialzed into cookie-cutter notions of one-size fits all. Suicide and the aftermath of experiencing suicide is an extremely traumatic experience for anyone regardless or culture or background. Ensuring that all people have access to support services is vital in suicide, grief, and loss work. If certain groups are not accessing help because services do not reach out and speak to them then it is our role as service providers and researchers to acknowledge why more is not being done to bring all peoples experiences to the forefront, and to examine the structures that exclude or only include only certain understandings to create knowledge from. Recall the quote from Dunbar (2008): "What there is to know is inextricably linked to an individual's past, present, and future. It is shaped by historical, social, political and economic experiences. My reality suggests that race matters" (p.86). If race matters, culture also matters; and understanding how South Asians view suicide and experience grief and loss is worth knowing. 


\section{References}

Armour, M. (2007). Violent death. Journal of Human Behavior in the Social Environment, 14(4), 53-90.

Beautrais, A. (2004) Suicide postvention support for families, Whanau and significant others after a suicide: A literature review and synthesis of evidence. Wellington, NZ: Ministry of Health.

Bhattacharya, G., \& Schoppelrey, S. L. (2004). Preimmigration beliefs of life success, postimmigration experiences, and acculturative stress: South Asian immigrants in the United States. Journal of Immigrant Health, 6(2), 83-92.

Bhardwaj, A. (2001) Growing up young, Asian and female in Britain: A report on self-harm and suicide, Feminist Review, (68), 52-67.

Breen, L., \& O'Connor,M. (2007). The fundamental paradox in the grief literature: A critical reflection. Omega, 55(3), 199-218.

Burck, C. (2005) Comparing qualitative research methodologies for systemic research: The use of grounded theory, discourse analysis and narrative analysis Journal of Family Therapy, $27(3), 237-262$.

Burman,E., Chantler k., \& Batsleer,J. (2002) Service responses to South Asian women who attempt suicide or self-harm: Challenges for service commissioning and delivery, Critical Social Policy, 22(4), 641-668.

Chase, S. (2003). Learning to listen: Narrative principles in a qualitative research methods course. In R. Josselson, A. Lieblich, \& D. P. McAdams (Eds.), Up close and personal: The teaching and learning of narrative research (pp. 79-100). Washington, DC: American Psychological Association. 
Charles, J. L. K., Holley, L. C., \& Kondrat, D. C. (2017). Addressing our own biases: Social work educators' experiences with students with mental illnesses. Social Work Education, $36(4), 414-429$.

Chew-Graham, C., Bashir, C., Chantler,K., Burman, E.( 2002) South Asian women, psychological distress and self-harm: Lessons for Primary Care Trusts, Health and Social Care in the Community, 10(5), 339-347.

Chou, R. S., \& Feagin, J. R. (2015). Myth of the model minority: Asian Americans facing racism. Boulder, CO: Routledge.

Collings S., \& Beautrais, A. (2005). Suicide prevention in New Zealand: A contemporary perspective. Wellington, NZ: Ministry of Health.

Clarke, D.E., Colantonio, A., \& Rhodes, A.E. (2008) Pathways to suicidality across ethnic groups in Canadian adults: The possible role of social stress. Psychological Medicine, 38, $419-431$.

Colucci,E., \&Martin,G. (2007). Ethnocultural aspects of suicide in young people: A systematic literature review Part 1: Rates and methods of youth suicide. Suicide \& Life-Threatening Behavior, 37(2), 197-221.

Colucci, E., \& Graham, M. (2007). Ethnocultural aspects of suicide in young people: A systematic literature review Part 2: Risk factors, precipitating agents, and attitudes toward suicide. Suicide \& Life-Threatening Behavior, 37(2), 222-237.

Cerel, J., Padgett, J., Conwell, Y. \& Reed, G. (2009). A call for research: The need to better understand the impact of support groups for suicide survivors. Suicide \& LifeThreatening Behavior, 39(3), 269-81.

Currer,C. (2007). Loss and social work. Exeter, UK: Learning Matters. 
Davis, A., \& Gentlewarrior, S. (2015). White privilege and clinical social work practice:

Reflections and recommendations. Journal of Progressive Human Services, 26(3), 191 208.

Drozdek,B., \& Wilson,J. (2007) Voices of trauma: Treating survivors across cultures. Postbus, The Netherlands: Springer.

Etzersdorfer, E., Vijayakumar, L., Schöny, W., Grausgruber, A., \& Sonneck, G. (1998).

Attitudes towards suicide among medical students: Comparison between Madras (India) and Vienna (Austria). Social Psychiatry and Psychiatric Epidemiology, 33(3), 104-110.

Dunbar, C. (2008). Critical race theory and Indigenous methodologies. In N. Denzin, Y. Lincoln, \& L.S. Smith (Eds.), Handbook of critical and Indigenous methodologies (pp, 85-99). Thousand Oaks, CA: Sage Publications..

Fraser, H. (2004). Doing narrative research: Analyzing personal stories line by line. Qualitative Social Work, 3(2), 179-201.

Haas, A. P., Eliason, M., Mays, V. M., Mathy, R. M., Cochran, S. D., D'Augelli, A. R., .. . Clayton, P. J. (2010). Suicide and suicide risk in lesbian, gay, bisexual, and transgender populations: Review and recommendations. Journal of Homosexuality, 58(1), 10-51. herising, F. (2005). Interrupting positions: Critical thresholds and queer pro/positions. In L. Brown \& S. Strega (Eds.), Research as resistance: Critical, Indigenous and antioppressive approaches (pp. 127-152). Toronto, ON: Canadian Scholars’ Press.

Hickson, H. (2016). Becoming a critical narrativist: Using critical reflection and narrative inquiry as research methodology. Qualitative Social Work, 15(3), 380-391. 
Hsaio-Rei Hicks, M., \& Bhugra, D. (2003). Perceived causes of suicide attempts by UK South Asian women. American Journal of Orthopsychiartry, 73(4), 455-462.

Humphrey, C. (2007). Insider-outsider: Activating the hyphen. Action Research, 5(11), 11-26.

Joe, S., Canetto,S., \& Romer,R., (2008). Advancing prevention research on the role of culture in suicide prevention. Suicide \& Life-Threatening Behavior, 38(3), 354-362.

Kasiram, M., \& Partab, R. (2002) Grieving through culture and community: A South African perspective. Social Work/Maastskaplike, 38(1), 39-44.

Kolivoski, K., Weaver, A., \& Constance-Huggins, M. (2014). Critical race theory: Opportunities for application in social work practice and policy. Families in Society: The Journal of Contemporary Social Services, 95(4), 269-276.

Kondrat, M. E. (1999). Who is the "self" in self-aware: Professional self-awareness from a critical theory perspective. The Social Service Review, 73(4), 451.

Kulke, H., \& Rothermund, D. (2004). A history of India (4th ed.) New York, NY: Routledge.

Larson, G. (2008). Anti-oppressive practice in mental health. Journal of Progressive Human Services, 19(1), 39-54.

Lester, D., Agarwal, K., \& Natarajan, M. (1999). Suicide in India. Archives of Suicide Research, $5(2), 91-96$.

Leach, M. (2006). Cultural diversity and suicide: Ethnic, religious, gender, and sexual orientation perspectives. New York, NY: The Haworth Press.

Leenaars, A. (2008). Suicide: A cross-cultural theory. In F. Leong, \& M. Leach. (Ed.), Suicide among racial and ethnic minority groups: Theory, research, and practice (pp. 13-37). New York, NY: Routledge/Taylor \& Francis Group. 
Leong, F.,\& Leach, M.(2008) Suicide among racial and ethnic minority groups. New York, NY: Routledge.

Marsh, I. (2010) Suicide: Foucault, history, and truth. New York, NY: Cambridge University Press.

McConnell, D., Hahn, L., Savage, A., Dubé, C., \& Park, E. (2016). Suicidal ideation among adults with disability in Western Canada: A brief report. Community Mental Health Journal, 52(5), 519-526.

Marecek, J. (1998). Culture, gender, and suicidal behaviour in Sri Lanka. Suicide and Life Threatening Behavior, 28(1), 69-81.

Mato, D. (2008). Transnational relations, culture, communication and social change, Social Identities, 14(3), 415-435.

McMenamy, J., Jordan, J., \& Mitchell, A. (2008). What do suicide survivors tell us they need? Results of a pilot study. Suicide \& Life-Threatening Behavior, 38(4), 375-89.

Nakayama, T. K., \& Krizek, R. L. (1995). Whiteness: A strategic rhetoric. Quarterly Journal of Speech, 81(3), 291-309.

Navaneelan, T. (2017). Suicide rates: An overview. Ottawa, ON: Statistics Canada. Retrieved from http://www.statcan.gc.ca/pub/82-624-x/2012001/article/11696-eng.htm

Ord, R. (2009). "It's like a tattoo": Rethinking dominant discourses on grief. Canadian Social Work Review, 26(2), 195-211.

Owens, A., \& Randhawa, G. (2004). It's different from my culture; they're very different: Providing community-based, 'culturally competent' palliative care for South Asian people in the UK, Health and Social Care in the Community, 12(5), 414-421. 
Parker, K., \& Lynn, M. (2002). What's race got to do with it? Critical race theory's conflicts with and connections to qualitative research methodology and epistemology. Qualitative Inquiry, 8(1), 7-22.

Petty, M. (2000). SOS and the retelling of Suicide. Health, 4(3), 288-308.

Reyes Cruz, M. (2008). What if I just cite Graciela? Working toward decolonizing knowledge through a critical ethnography. Qualitative Inquiry, 14(4), 651-658.

Riessman C.,K., \& Quinney, L. (2005). Narrative in social work: A critical review. Qualitative Social Work, 4(4), 391-412.

Sands,D., \& Tennant,M. (2010). Transformative learning in the context of suicide bereavement. Adult Education Quarterly, 60(2), 99-121.

Sakamoto,I. (2007). An anti-oppressive approach to cultural competence. Canadian Social Work Review, 24, 105-114.

Sarma, A. (2014). Parental pressure for academic success in India (Doctoral Dissertation). Retrieved from ProQuest Dissertations \& Theses Global, 3633281.

Shiang, J. (1998). Does culture make a difference? Racial/ethnic patterns of completed suicide in San Francisco, CA 1987-1996 and clinical applications. Suicide and Life-Threatening Behavior, 28(4), 338-354.

Somerville, K., \& Robinson, O. (2016). Keeping up appearances within the ethnic community: A disconnect between first and second generation South Asians' educational aspirations. Canadian Ethnic Studies, 48(2), 99-117.

Srivastava, S. (1996). Song and dance? The performance of antiracist workshops. Canadian Review of Sociology/Revue canadienne de sociologie, 33(3), 291-315. 
Statistics Canada (2007). The South Asian community in Canada. Ottawa, ON: Author. Retrieved from http://www.statcan.gc.ca/pub/89-621-x/89-621-x2007006-eng.htm

Takahashi, Y. (1997). Culture and suicide: From a Japanese psychiatrist's perspective. Suicide \& Life-Threatening Behavior, 27(1), 137-145.

Turney, D. (1997). Hearing voices, talking difference: A dialogic approach to anti-oppressive practice. Journal of Social Work Practice, 11(2), 115-125.

Vijaykummar (2008) India. In Yip, P. (Ed.), Suicide in Asia: Causes and prevention (pp. 1-9). Aberdeen, HK: Hong Kong:University Press.

Valentine, C. (2006). Academic constructions of bereavement. Mortality, 11( 1), 57-78.

Valentine, C. (2008). Bereavement narratives. New York, NY: Routledge.

Vandecreek, L., \& Mottram, K. (2009). The religious life during suicide bereavement: A description. Death Studies, 33(8), 741-761.

Willis,J. \& Sands,M. (2007). Research in a post-colonial world: The example of Australian Aborigines. In M. Pitts, M., \& A. Smith (Eds.), Researching the margins: Strategies for ethical and rigourous research with marginalised communities (pp. 96-113). New York, NY: Palgrave Macmillan.

Winkel, H. (2001). A postmodern culture of grief? On individualization of mourning in Germany. Mortality, 6(1), 65-79.

Wong, Y., \& Vinsky, J. (2009). Speaking from the margins: A critical reflection on the "spiritual-but-not-religious" discourse in social work. The British Journal of Social Work, 39(7), 1343-1359. 